\title{
FUNDAMENTALITY AND THE EXISTENCE OF GOD
}

\author{
JOSHUA R. SIJUWADE \\ https:/ / orcid.org/0000-0003-4412-7794 \\ London School of Theology \\ Department of Philosophy \\ United Kingdon og Great Britain and Northern \\ Ireland \\ joshua.sijuwade@1st.ac.uk
}

\section{Article info \\ CDD: 200.1}

Received: 15.06.2021; Revised: 30.06.2021; Accepted: 19.08.2021

https://doi.org/10.1590/0100-6045.2021.V44N4.JS

\section{Keywords}

Fundamentality

Grounding

Metaphysical Explanation

God

Abstract: In this article, I seek to assess the extent to which Theism, the claim that there is a God, can provide a true fundamental explanation for the existence of certain entities within the layered structure of reality. More precisely, I assume the cogency of Swinburne's explanatory framework and seek to resituate it within a new philosophical context-that of the field of contemporary metaphysics - which will enable me to develop a true fundamental explanation for the existence of the nonfundamental entities that fill up the various levels of the layered structure of reality. And thus, given the truth of this type of explanation, we will have one more good reason to believe in the existence of God. 


\section{Introduction}

According to Richard Swinburne (2004, 2010), Theism, the claim that there is a God, provides a true explanation of the existence of the universe and its features. Theism is thus taken by Swinburne and others to be the ultimate explanation for there being a universe, and it being conformed to simple natural laws that lead to the evolution of conscious and morally aware human agents. In this article, I seek to assess the extent to which Theism can also provide a true fundamental explanation for the existence of certain entities within the layered structure of reality. More precisely, I assume the cogency of Swinburne's explanatory framework and seek to resituate it within a new philosophical contextthat of the field of contemporary metaphysics - which will enable me to develop a true fundamental explanation for the existence of the non-fundamental entities that fill up the various levels of the layered structure of reality. And thus, given the truth of this type of explanation, we will have in front of us a new abductive argument for the existence of God-specifically, an argument for God's existence based on the fact of him being the best (fundamental) explanation for the existence of the non-fundamental entities that reside within the layered structure of reality. ${ }^{1}$ Hence, at the end of

${ }^{1}$ An abductive argument is a type of argument for the truth of a conclusion that employs 'abductive reasoning'. Abductive reasoning is a form of reasoning that typically starts with a set of data and proceeds from this set, to the 'best' explanation for it, in accord with a certain explanatory criteria. Thus, the type of argument that will be formulated in this article is of this kindthough it will be stated at an informal level. For a further explanation of the nature of abductive reasoning, and a comparison of this type of reasoning with that of deductive and inductive reasoning, see (Douven, 2021).

Manuscrito - Rev. Int. Fil. Campinas, v. 44, n. 4, pp. 93-168, Oct.-Dec. 2021. 
our exploratory journey, we will thus have one more good reason to believe in the existence of God.

Plan: in section 2 ('Explanatory Framework'), I detail the nature of Swinburne's explanatory framework and resituate it within a metaphysical context. In section 3 ('Explanatory Target'), I explain the specific explanatory target that is under focus - the existence of non-fundamental entities. In section 4 ('Explanatory Analysis'), I assess Theism and two other candidate fundamental explanations of our explanatory target: Priority Monism and Priority Pluralism. Each of these explanations will be assessed in light of their fulfilment of the inductive criteria detailed in section 1 , with the final conclusion being that Theism is the only explanation that fulfils this criteria - it is the simplest explanation, fitting with our background knowledge, that leads us to expect the data, when otherwise it would not be expected. Theism is thus the best candidate to be a fundamental explanation of the existence of the various non-fundamental entities that are part of the layered structure of reality. Finally, there will be a concluding section ('Conclusion') that will summarise the position that has been argued for in this article.

\section{Explanatory Framework}

\subsection{Nature of Explanation}

The provision of an explanation, as noted by Swinburne (2004, 23), is an ambiguous exercise-it may refer, on the one hand, to someone having provided a true explanation of a phenomenon, or, on the other hand, it may mean that the person has merely provided a possible explanation of it. Nonetheless, when one is indeed seeking an explanation of the occurrence of a given phenomenon, they are certainly interested in arriving at a true, rather than simply a possible, 
explanation of it. Thus, understanding the nature of a true explanation, rather than solely that of a possible explanation, will be our main focus. A true explanation, within a general causal context, is provided for the occurrence of some phenomenon (i.e. an event) when one states a set of factors that include within it a 'cause' (i.e. an object and the set of conditions in which it was operative) and the 'reason' that the cause was operative in the manner that it was. ${ }^{2}$ More fully, we can construe the nature of a true (general) explanation as such:

(1) (General Explanation) An explanation is a true explanation of the occurrence of a given phenomenon when it invokes a what (i.e. a cause) that truly brought about the phenomenon and a why (i.e. a reason) that explains its efficaciousness.

Once these factors are in place - the what and why — we have a true explanation for the occurrence of a particular event. More specifically, a true general explanation provides the correct answer to questions concerning what caused a particular event to occur and why that event occurred in the manner that it did. In addition to this, a general explanation is also focused on providing a diachronic explanation for the occurrence of a particular event by the invoking of a cause and a reason that were operative over a certain period of time. Moreover, within this particular explanatory framework, there are two kinds of explanation: inanimate explanation and personal explanation. An inanimate explanation is an explanation that invokes, first, an initial

2 The word 'general' is only used here and below to distinguish this type of explanation from that of a metaphysical explanation.

Manuscrito - Rev. Int. Fil. Campinas, v. 44, n. 4, pp. 93-168, Oct.-Dec. 2021. 
state of affairs - which will include an operating cause - and second, some laws of nature-which are universal generalisations of the form 'all A's are so-and-so' or 'all A's do so-and-so'-in order to explain the occurrence of a particular event (Swinburne, 2004, 26). More specifically, an inanimate explanation is distinctive in its inclusion of inanimate causation - and thus the what is the initial conditions that include the cause, and the why is the law of nature that was operative at the specific time in which the particular event occurred. Thus, for example, the occurrence of an explosion is explained by the ignition of a particular volume of gunpowder under certain conditions-which is the what - in combination with a generalisation that under such conditions ignited gunpowder explodes - which is the why (Swinburne, 2004, 26). Personal explanation, on the other hand, involves persons, their beliefs and purposes. More precisely, a personal explanation is distinctive in its inclusion of intentional causation - and so the what is the person, and the why are the beliefs, powers and purposes of that person. So, for example, the occurrence of a hand wave is explained by a person-which is the what-in combination with their power to wave their hand, their belief that waving their hand will catch the attention of someone, and their purpose of catching the attention of a certain individual — each of which constitute the why.

Taken together, we thus have two kinds of explanation for the occurrence of a particular event-inanimate and personal explanation-which can then be understood to come in at least three different forms: partial explanation, full explanation and complete explanation. First, a partial explanation is a form of explanation that includes factorsa cause and a reason-that only contributed to the bringing about the occurrence of the phenomena under questionthe factors made it physically probable that they would occur, yet these particular factors did not necessitate the 
occurrence of the phenomena. For example, for an inanimate explanation, an individual contracting Huntington Disease is partially explained by their parent having had the disease. And, for a personal explanation, an individual having died from lung cancer is partially explained by them having smoked throughout their life. Within both kinds of explanation, the occurrence of the latter events only makes it probable but does not necessitate the occurrence of the former events. Second, a full explanation is a form of explanation that includes a set of factors - a cause and a reason-that were together sufficient for the occurrence of the phenomena-these set of factors are a 'full cause' of the phenomena and thus deductively entail, and really explain, its occurrence. For example, for an inanimate explanation, the occurrence of a high tide is fully explained by the sun, moon, earth, water, etc., being in certain positions and by the operation of Newton's laws (Swinburne, 2004, 78). And, for a personal explanation, a fridge door being left open is fully explained by an individual having opened it in order to get some food. Within both kinds of explanation, the occurrence of the former events is deductively entailed, and really explained by the occurrence of the latter events. Third, a complete explanation is a special form of full explanation that goes beyond this form by including within it a set of factors - a cause and a reason-of which there is no explanation (either full or partial) of their existence or operation in terms of contemporaneous factors that exist and are operative at the time of their existence or operation. ${ }^{3}$

${ }^{3}$ At a more specific level, this form explanation is a synchronicrather than diachronic-form of explanation. (Swinburne, 2004, n3) brings this out. However, as the causes invoked by this form of explanation are not simultaneous with their effects I will continue to class this form as a diachronic form of explanation. 
In other words, the what and why-that is, the cause and the operative reason-do not have any further explanation for their existence or operation on the basis of contemporaneous factors - they serve as the terminus in explanation for a given phenomenon at a specific time. For example, for an inanimate explanation, the occurrence of a high tide is completely explained by the specific region of the universe being relatively empty of matter and the operation of Albert Einstein's laws of General Relativity (Swinburne, 2004, 78). And, for a personal explanation, an individual having formed the intention to get some food from the fridge is completely explained by their further intention to eat regular meals in order to survive. Within both kinds of explanation, the occurrence of the former event (or state) is deductively entailed, and really explained, by the occurrence of the latter event (or state), and of which there is no further explanation in the form of contemporaneous factors for the occurrence of the latter events (or states) — these factors are the terminus in explanation for that specific phenomenon at a given time.

Now, this explanatory framework-that includes the different kinds and forms of a true explanation-can now also be extended into the metaphysical realm. However, in doing this, we also realise that with a true, general explanation, the provision of a metaphysical explanation is an ambiguous exercise as well. Yet, despite this ambiguity, a minimal understanding of a true metaphysical explanation, as noted by individuals such as Anna Sofia-Maurin (2019, 1574), is that of it invoking entities and a non-causal explanatory connection, which accounts for the nature and/or existence of one entity with reference to another entity, that the former non-causally and synchronically depends upon. More precisely, and expounding this within our explanatory framework, we can construe the nature of a true metaphysical explanation as such: 
(2) (Metaphysical Explanation) An explanation is a true metaphysical explanation of the nature and/or existence of a given entity when it invokes a what (i.e. a ground) that the entity noncausally and synchronically depends upon and a why (i.e. a principle) that explains the reason for the dependence of the former entity on the latter entity.

Once these factors are in place-the what and why-we have a true metaphysical explanation for the nature and/or existence of a given entity at a specific time. More specifically, a true metaphysical explanation provides the correct answer to questions of what determines or makes one entity exist and be what it is. Moreover, a metaphysical explanation, unlike a general explanation, is focused on providing a synchronic explanation for the constitutive generation of a dependent outcome at a specific point in time. And this is done by invoking an entity and a principle or, more specifically, following Jonathan Schaffer (2017, 305), a 'law of metaphysics' - which is simply that of a counterfactual-supporting general principle stating what builds or grounds what. ${ }^{4}$ Now, as with a general explanation, there are at least two possible kinds of metaphysical explanation: inanimate metaphysical explanation and personal metaphysical explanation. An inanimate metaphysical explanation is one that invokes an entity and a law of metaphysics in order to explain the nature and/or existence of another entity - the what is the former entity and the why is the holding of the law between it and the latter entity. Whilst, a personal metaphysical explanation is one that invokes an entity, the beliefs, powers and purposes of that

${ }^{4}$ More on the nature of building and grounding below. 
entity and a law of metaphysics in order to explain the nature and/or existence of another entity-the what is the former entity and the why are the beliefs, powers and purposes of that entity and the holding of the law between it and the latter entity. In the metaphysical domain, and unlike in the general explanatory domain detailed above, inanimate and personal metaphysical explanations converge-that is, laws of metaphysics are present in both-where the only difference between these two different kinds of explanation is that a personal metaphysical explanation, and not an inanimate metaphysical explanation, includes the beliefs, powers and purposes of an entity as an explanatory factor for the constitutive generation of a dependent outcome.

As with the general explanatory case, a metaphysical explanation of both kinds can come in three different forms. It can, first, be a partial metaphysical explanation, which is a form of metaphysical explanation that includes factors - an entity and a law of metaphysics - that another entity is only partially (non-causally and synchronically) dependent upon. For example, for an inanimate metaphysical explanation, the existence of an $\mathrm{H}_{2} \mathrm{O}$ molecule is partially explained by the existence of an $b$ atom. And, for a personal metaphysical explanation, the existence of a musical harmony at a certain time is partially explained by the existence of one individual who is singing a note at that specific time. Within both kinds of explanation, the existence of the latter entities does not necessitate the existence of the former entities. Second, a full metaphysical explanation is a form of a metaphysical explanation that includes factors - an entity and a law of metaphysics - that another entity is fully (non-causally and synchronically) dependent upon-the entity (or entities) that constitutes a part of the explanatory set of factors is (or are) a 'full ground' of the other entity and thus deductively entail, and really explain, its existence. For example, for an inanimate metaphysical explanation, the existence of an $\mathrm{H}_{2} \mathrm{O}$ 
molecule is fully metaphysically explained by the existence and arrangement of two $h$ atoms and an $O$ atom. And, for a personal metaphysical explanation, the existence of a musical harmony at a certain time is fully metaphysical explained by the existence of two individuals who are singing a note at that specific time. Within both kinds of explanation, the existence (and arrangement) of the latter entities deductively entails, and really explains, the existence of the former entities. Third, a complete metaphysical explanation is a special form of metaphysical explanation that includes factors - an entity and a law of metaphysics - that another entity is fully (non-causally and synchronically) dependent upon, and which their existence is not (non-causally and synchronically) dependent upon another contemporaneously existing entity. In other words, the what and why-that is, the existence of the latter entity (and/or law) - is the fundamental reason for the former entity existing. So, given the importance of the notion of fundamentality for this form of explanation, we can now re-term a complete metaphysical explanation as a fundamental explanation. Thus, for example, and to pre-empt the main discussion of this article, for an inanimate fundamental explanation, it could be the case that the existence of non-fundamental entities is fundamentally explained by the existence of the Cosmos (or a collection of mereological atoms). Or, for a personal fundamental explanation, it could be the case that the existence of nonfundamental entities is fundamentally explained by the existence of God. Within both kinds of explanation, the existence of the latter entities deductively entails, and really explains, the existence of the former entities, and of which there is no further explanation, in the form of contemporaneous, or, more fundamental factors, for the former entities existing as they do. Taking all of this into account, these are the different kinds and forms of explanation that are available within a non-metaphysical and metaphysical 
context. The important question to be faced now then is: what are the justificatory grounds for one believing that they have acquired a true complete explanation for the occurrence of a given phenomenon or a fundamental explanation for the existence of a given entity?

\subsection{Justification of Explanation}

The justificatory grounds on which an explanation is judged to be a correct terminus in explanation-that is, how probable it is that this explanation is a complete or fundamental explanation of a particular event or entitycentres on the extent to which it fulfils the following inductive criteria: ${ }^{5}$

(i) The Criterion of Predictive Power

(ii) The Criterion of Background Knowledge

(iii) The Criterion of Scope

(iv) The Criterion of Simplicity

For (i): the Criterion of Predictive Power, this criterion assesses whether the postulated explanation predicts the occurrence of the event, or the existence of the entity, when otherwise this event or entity would not be expected to have occurred or to have existed. Importantly, however, as Swinburne $(2004,70)$ notes, the ability for an explanation (of

5 Knowledge concerning the truth of this inductive criteria, according to Swinburne (2001, 122), is obtainable a priori. Furthermore, this criteria is taken to be at the heart of scientific and historical practice - that is, scientists and historians, according to Swinburne $(2001,74)$, regularly employ this inductive criteria in their investigations.

Manuscrito - Rev. Int. Fil. Campinas, v. 44, n. 4, pp. 93-168, Oct.-Dec. 2021. 
a general and metaphysical kind) to predict the data does not imply that this explanation has to do this in a literal sense (i.e. that the event or entities that constitute the data will be observed to have occurred or to exist in the future). Rather, an explanation is only required to provide a sufficient explanation for the data, whether or not this data was obtained in the past. For (ii): the Criterion of Background Knowledge, this criterion assesses whether the postulated explanation meshes with other explanations that are rendered probable by this inductive criteria. That is, an explanation fits with background knowledge if the causes or entities invoked by the explanation are similar to those causes or entities that are taken to exist within other neighbouring fields. ${ }^{6}$

For (iii): the Criterion of Scope, this criterion assesses how much the postulated explanation seeks to explain. Generally, an explanation that seeks to explain more data is less probably true than one that is more restricted in its explanatory range. However, as Swinburne $(2004,56)$ sees it, this criterion is not to be given very much weight, since the

6 Swinburne $(2004,60)$ sees the Criterion of Background Knowledge as being limited in its usage, in that it is only applicable to explanations that have a narrow scope as, according to Swinburne, the amount of evidence that reside within the background knowledge, with which a given explanation will need to fit will decrease the range of its scope. Thus, in Swinburne's thought, there will not be any background knowledge that an explanation of enormous scope will need to fit with. In response to this, Herman Philipse (2012, 210-212) has argued that Swinburne's reasoning in support of one eliminating the Criterion of Background Knowledge is fallacious - it is subject to the 'fallacy of division'-and thus must be abandoned. Adjudicating this debate will take us to far afield, and thus going forward we will simply continue to maintain this specific inductive criterion for our analysis of the candidate fundamental explanations. 
specific restrictions of the scope of an explanation are often arbitrary and complicated, and thus explanations that have a narrower scope are-although more probably truetypically less simple than explanations of a much wider scope. Thus, given the importance of the Criterion of Simplicity, which is to be seen now, the Criterion of Scope is generally less important for determining the probable truth of an explanation. For (iv): the Criterion of Simplicity, this criterion assesses whether the postulated hypothesis is quantitatively and qualitatively simple. The quantitative and qualitative simplicity of an explanation is that of it postulating the fewest entities, fewest properties of entities, fewest kinds of entities, fewest kinds of properties, properties that are more readily observable, the fewest separate laws with the fewest terms relating the fewest variables, and the simplest formulation of each law being mathematically simple (Swinburne, 2004, 53). In following Schaffer $(2015,647),{ }^{7}$ however, one will need to modify this criterion within a metaphysical context by focusing the quantitative and qualitative simplicity of an explanation on that of fundamental entities, principles or laws, rather than all types of entities, principles or laws. A probably true

${ }^{7}$ Schaffer (2015), in a similar manner to Swinburne, also sees the importance of the Criterion of Simplicity (or 'Occam's Razor') for metaphysical theorising. However, Schaffer believes that one must also include a specific restriction to the range of the Razor, which is that of it only to being applicable to fundamental entities and/or properties - Schaffer terms this additional restriction the 'Laser'. Interestingly, however, Schaffer's Laser does not distinguish between quantitative and qualitative simplicity. Nevertheless, there is nothing inherent within the Laser that should stop one from making this distinction. 
fundamental explanation is thus one that is quantitatively and qualitatively simple. The quantitative and qualitative simplicity of a fundamental explanation is thus that of it postulating the fewest fundamental entities, fewest properties of fundamental entities, fewest kinds of fundamental entities, fewest kinds of fundamental properties, fundamental properties that are more readily observable, the fewest separate metaphysical laws with the fewest terms relating the fewest variables and the simplest formulation of each metaphysical law being mathematically simple. Nevertheless, for both explanations-general and metaphysical - if an explanation posits the existence of some new particular object or properties, it is required by the Criterion of Simplicity that it should postulate as few as possible, and it should postulate no more than those that are needed to explain the observational data.

This is the inductive criteria that provide justificatory grounds for holding to the probable truth of a particular explanation. Within both kinds of explanation, we seek the simplest explanation, fitting with our background knowledge, which leads us to expect the phenomena or entities that do in fact occur or exist, when otherwise this would not be expected. And the fulfilment of these criteria is the grounds for one determining the stopping point for a purported complete or fundamental explanation. Focusing our attention from here on fundamental explanations, a full metaphysical explanation of the existence of a collection of entities is a fundamental explanation, if we believe that the existence of the entities under question could only be explained further by postulating further full grounds acting contemporaneously with the entities, which do not have any more simplicity, greater fit with background knowledge and predictive power than the full grounds (and laws) featured in the former explanation-these full grounds would serve as the terminus of explanation. One would thus be justified in 
taking a certain candidate explanation to be a fundamental explanation if one had reason to believe that any particular gain in the fulfilment of one of the inductive factors (i.e. simplicity, fit with background knowledge or predictive power) would be outweighed by a corresponding loss of another. Thus, for example, any attempt to provide an alternative explanation of the existence of a given entity would result in one postulating a more complex explanation - and thus, it fails to fulfil Criterion (iv) - with only a potentially marginal gain in predictive power (or fit with background knowledge). One is thus to move beyond the data, and the currently existing explanations of it, only if there is a possibility of a greater fulfilment of the inductive criteria, and that will be so if there is a potential explanation that is simpler and/or explains the data better, whilst still fitting with background knowledge. Thus, in regards to Theism, and whether it can serve as a fundamental explanation of a certain set of metaphysical data, one will need to establish whether Theism, relative to the data, sufficiently meets the inductive criteria. And if it does, given the nature that God is taken to have, he must serve as a fundamental explanation of this data. In short, once we establish that Theism is probably true-that is, it is the simplest explanation, fitting with our background knowledge, that led us to expect the data, when otherwise it would not be expected - then one has reached a terminus in explanation. So, the question that is now presented to us is: what is the nature of the particular phenomenon that we are seeking a fundamental explanation of? In other words, what is our explanatory target? And how does Theism and any other potential explanation seek to explain it? 


\section{Explanatory Target}

\subsection{Layered Structure of Reality}

The human quest for knowledge seeks a fundamental explanation for the existence of all dependent things - that entity or entities on which everything else depends for its nature and/or existence. As will be explained below, we certainly will need to acknowledge something as fundamental, and so the great metaphysical issue is understanding what exactly that is. There are at least two types of fundamental explanations available: an inanimate fundamental explanation and a personal fundamental explanation, each of which posits the existence and operation of fundamental entities that purportedly explain the existence of other dependent entities - that is, nonfundamental entities - when otherwise these entities would not be expected to exist. More specifically, we can take the following phenomenon as our explanatory target:

(3) (Explanatory Target) There are nonfundamental entities, rather than none at all.

This explanatory target captures certain phenomena whose existence require a further, more fundamental explanation. In the next section, we will map out the available candidate fundamental explanations and assess which of these candidates is most probably the correct one. Prior to that, it will be helpful to further sketch out the metaphysical picture and framework within which our explanatory target can be located. Specifically, it is an evident fact of reality that a variety of different things exist, ordered from the very large things (e.g. planets, stars and galaxies) passing through the more medium-sized things (e.g. flamingos, humans and buildings) to the very small things (e.g. quarks, protons and 
neutrons). Some of these types of things are taken to be dependent entities that are, in some sense, less important than some other things within this structure. Flamingos, for example, appear to depend upon the existence of planets and stars - and all would agree, though flamingos are important as a species-without our planet and star existing in the here and now, flamingos will also not exist in the here and now, and not vice versa. Nonetheless, it is quite clear to most metaphysicians that the variety of content that makes up our reality is arranged into layers, or a hierarchy of levels: galaxies reside at the 'top-level' and thus are at a higher level than flamingos, that reside at the 'middle-level', which are themselves, in turn, at a higher level than quarks, that reside at the 'bottom-level' of this structure. Or, moving away from an ordering by size, and at a more scientific or categorial level, economics resides at the 'top-level', and is thus at a higher level than psychology, biology and chemistry, ${ }^{8}$ which reside at the 'middle-level', and thus are themselves, in turn, at a higher level than physics, which resides at the 'bottomlevel' of this specific structure. Reality is thus multi-layered with an increasing level of importance as you descend down its levels, or, as we will see below, as you ascend higher up its levels. So, given this layered view of reality, an important question that needs to be answered is: what makes a certain phenomenon higher (or lower) and thus less important (or more important) than another? A plausible answer to this question is that of each of the phenomena being connected and ordered by a relation of dependence and determination, which provides a basis for this hierarchical structure. Thus, focusing now on the scientific classificatory scheme: some phenomenon of economics: goods and services, is dependent upon, and determined by, some phenomenon of

${ }^{8}$ These categories are themselves ordered within this specific level.

Manuscrito - Rev. Int. Fil. Campinas, v. 44, n. 4, pp. 93-168, Oct.-Dec. 2021. 
psychology: the mind, which is dependent upon, and determined by, some phenomenon of biology: the brain, which is dependent upon, and determined by, some phenomenon of chemistry: matter or chemical states, which is dependent upon, and determined by, some phenomenon of physics: quarks. Given this hierarchical scheme, some metaphysicians take the categories residing within the lower levels of this structure (e.g. physics) to be more fundamental than those residing within the higher levels (e.g. biology and economics), with an explanation for the entities that exist in the higher levels ultimately terminating in the existence of an absolutely fundamental entity, or entities, that exist within the lower levels. An important question to be asked now is: what does it mean for something to be absolutely fundamental and more fundamental than another?

\subsection{Absolute \& Relative Fundamentality}

In contemporary metaphysics, the notion of absolute fundamentality is used in reference to an entity (or entities) that is (or are) basic, primitive or rock-bottom in the hierarchical structure of reality. Two central aspects of the notion of absolute fundamentality, according to Karen Bennett (2017), are those of independence and completeness (with the former being more central to the notion than the latter). ${ }^{9}$ Given these two aspects, a distinctive conceptualisation of the notion of absolute fundamentality can be stated as such:

\footnotetext{
${ }^{9}$ For the reasons for privileging independence over completeness, see (Bennett, 2017, 122-123).
} 
(4) (Fundamental) $x$ is fundamental if $x$ is independent and complete.

In Bennett's thought, absolute fundamentality, construed as independence and completeness, is intimately tied to the further notion of building. Building is a technical term that ties together the following type of relations: composition, constitution, set-formation, realisation, micro-based determination, grounding and causation. These various relations are not intended by Bennett to be exhaustive but are instead relatively central notions that intuitively fit the mould of being a building-relation. How these paradigm relations fit this building mould is through them fulfilling the three necessary and jointly sufficient conditions of directedness, necessitation and generation. Firstly, the condition of directedness takes a building-relation to be antisymmetric, irreflexive and thus asymmetric. Secondly, the condition of necessitation takes builders to necessitate, in some sense, what they build. Thirdly, the condition of generation takes the built entities to exist in virtue of their builders, and thus the latter back an explanation for the former existing as they do (Bennett, 2017, 32). These necessary and sufficient conditions distinguish building-relations from other types of relations and provide a basis for the claim that buildingrelations form a unified family (i.e. a natural resemblance class) despite the differences amongst them (Bennett, 2017, 20). Off of the basis of this further explication of the notion of building, we can now construe the independence aspect of absolute fundamentality as such:

(5) (Independence) $x$ is independent if nothing builds $x$ (Bennet, 2017).

And we can now also construe the completeness aspect of absolute fundamentality as such: 
(6) (Completeness) The set of the $x x s$ is (or the $x x s$ plurally are, or a non-set-like $x$ is) complete at a world $w$ just in case its members build (...) everything else at $w$ (Bennett, 2017, 109).

According to (Independence), absolutely fundamental entities are independent in the sense that they are unbuilt and thus do not depend on anything else. Moreover, for (Completeness), a certain set of absolutely fundamental entities are complete at a specific world in the sense that they build everything else in that world. That is, they are the things that ultimately account for everything else that does exist in that specific world. Absolute fundamentality, as expressed by (Fundamental) and further elucidated by (Independence) and (Completeness), reflects, as Bennett $(2017,111)$ notes, two halves of the familiar phrase 'unexplained explainers', the 'unexplained' part reflecting independence which says that nothing 'presses upwards' on them and the 'explainers' part reflecting completeness which says that a certain set of entities 'presses upwards' on everything else in a specific world. Furthermore, and more importantly, these two aspects are reducible to and defined by the notion of building. That is, within the building-fundamentality framework, there is thus a deflationism (or reductionism) about absolute fundamentality, where the fundamentality facts are simply the building facts (Bennett, 2017). Therefore, as Bennett notes, for certain fundamentality relations to obtain is simply 'for certain complex patterns of building to obtain' (Bennett, 2017, 139). In short, there is an identification of absolute fundamentality with building. Thus, the state of affairs of an entity being absolutely fundamental is that of them being independent and complete, which is reducible to the entity being, on the one 
hand, unbuilt and, on the other hand, part of a set at a world whose members build everything else in that specific world. However, it is important to remember that there is not a single, general relation of building. Rather there are a different number of building-relations that form a unified family. Thus, when the term 'building' is used in a singular sense, it is simply a generalisation about a class of relations (Bennett, 2017, 3). Therefore, absolute fundamentality, construed as independence and completeness, is to be indexed to particular building-relations. Hence, in indexing absolute fundamentality to particular building-relations, to be absolutely fundamental is to be independent and complete, which, for the former, is ultimately reducible to either not being composed, or constituted, or realised, or determined, or grounded, or caused, by anything else-an absolutely fundamental entity does not feature as an output of a particular building-relation (Bennett, 2017, 112). Whereas, for the latter, it is ultimately reducible to being a member of a set of entities at a world whose members compose, or constitute, or realise, or determine, or ground, or cause everything else, in that specific world - the set of absolutely fundamental entities builds, in one of the above ways, everything else (Bennett, 2017, 112). Thus, there are various real distinctions between the indexed versions of absolute fundamentality. ${ }^{10}$ Focusing our attention now on one particular building-relation: grounding, we can see that this relation is regularly characterised as a primitive expression of dependence, determination or explanation. This expression has been championed by 'grounders' (i.e. grounding theorists) such as Kit Fine (2012), Jonathan Schaffer (2009a and 2016) and Gideon Rosen (2010),

${ }^{10}$ From this point on I will alternate between the term 'absolutely fundamental' and 'fundamental' without any change in meaning.

Manuscrito - Rev. Int. Fil. Campinas, v. 44, n. 4, pp. 93-168, Oct.-Dec. 2021. 
amongst others, ${ }^{11}$ and is typically introduced by paradigm example(s) such as the following:

(7) (Paradigm) Singleton-Socrates exists in virtue of the existence of Socrates.

What is of concern in this example for grounders, is not so much the truth value of the claim, but rather the fact that the connecting 'in virtue' clause (and others like it) expresses some form of ontological priority that is related to 'determination', 'dependence' or 'explanation'. However, in explicating the nature of this ontological priority and the character of this expression, grounders usually focus on detailing the specific formal principles, modal pattern, explanatory and generative roles, and the analogous relationship to other relations which grounding has, which all help to further demystify it. So, in following this demystification procedure, we can see that the consensus for grounders is that grounding, in its standard 'full' variety: ${ }^{12}$

(8) (Full) A given $x$ is the ground of $y$ if $x$ on its own is sufficient to ground $y$.

is, firstly, governed by the following three formal principles: ${ }^{13}$

11 For a historical explanation of these individuals' roles in developing the notion of ground, see (Raven, 2020).

${ }^{12}$ For a further detailing of this variety of ground, and the other varieties of ground such as the partial, immediate, mediate, weak and strict varieties, see (Fine, 2012, 51-53).

${ }^{13}$ However, all of these formal principles are indeed controversial. Thus, firstly, for issues with asymmetry, see (Rodriguez-Pereyra, 
(9) (Irreflexivity) No $x$ is grounded in itself.

(10) (Asymmetry) If $x$ grounds $y$, then $y$ does not ground $x$.

(11) (Transitivity) If $x$ grounds $y$, and $y$ grounds $z$, then $x$ grounds \%

And, secondly, grounding is also generally taken to be governed by the following principles that express a modal pattern: ${ }^{14}$

(12) (Non-monotonicity) If $x$ grounds $y$, it does not follow that $y$ is grounded by $x$ and any other fact (or entity) $r$.

(13) (Hyperintensionality) If $x$ grounds $y$, it does not follow that $x$ grounds any fact (or entity) that is intensionally equivalent to $y$.

(14) (Necessitarianism) If $x$ grounds $y$, then $x$ necessitates $y$.

Thus, given the formal principles, grounding induces a strict partial order over the entities that are in its domain (Trogdon, 2013). ${ }^{15}$ That is, grounding gives rise to a hierarchy of

2015). Secondly, for issues with irreflexivity, see (Jenkins, 2011). Thirdly, for issues with transitivity, see (Schaffer, 2012).

${ }^{14}$ Firstly, for an explanation of the non-monotonicity of ground, see (Audi, 2012). Secondly, for an explanation of the hyperintensionality of ground, see (Jenkins, 2011). Thirdly, for an extended explanation of necessitarianism, see (Trogdon, 2013). And for issues with it, see (Leuenberger, 2013). For a defense of it, see (Cameron, 2008).

15 For arguments against ground being a 'strict' order, see (Rodriguez-Pereyra, 2015). For a defense of ground as a 'strict' order, see (Raven, 2015).

Manuscrito - Rev. Int. Fil. Campinas, v. 44, n. 4, pp. 93-168, Oct.-Dec. 2021. 
grounds, in which the grounds of a fact (or entity), as Johannes Korbmacher notes, 'rank 'strictly below' the fact (or entity) itself (Korbmacher, 2018, 161, parenthesis added). And, given the principles that express a modal pattern, grounding entails a necessary dependence of the grounded on the grounds, in that the existence of the latter entails the existence of the former. In short, grounders guarantee what they ground (Trogdon, 2013). However, they perform this necessitating action in a 'fine-grained', rather than a 'coarsegrained' manner, in that they do not necessarily ground other superfluous entities as well. Thus, grounding, in its most basic construal, is an expression that conveys some form of directedness and necessitation. However, to aid us in our precisification task, it will be helpful to now narrow our focus to unpacking a specific ground-theoretic framework that has played an influential role within the contemporary literature, that of Jonathan Schaffer's grounding theory. Within this theory proposed by Schaffer, grounding is best modelled as a primitive 'directed-dependency' relation associated with the notion of ontological priority. This directed-dependency relation takes in terms from any arbitrary ontological category and links a more fundamental input to a less fundamental output (Schaffer, 2016). ${ }^{16}$ Thus, according to Schaffer (2009a), there is an ontological ordering within reality, in that some entities are derivative of other, more fundamental entities. The fundamental entities of reality ontologically undergird the derivative entities and grounding is the relation that connects the undergirding entity to entities that are at a higher level in the structure of reality. Thus, within this perspective, there is a hierarchical view of reality that is ordered by priority in

${ }^{16}$ For a different, but highly influential conception of ground, that does not take it to be a relation, but a sentential operator that has facts within its purview, see (Fine, 2012).

Manuscrito - Rev. Int. Fil. Campinas, v. 44, n. 4, pp. 93-168, Oct.-Dec. 2021. 
nature. Once one distinguishes more from less fundamental entities, it is natural to posit a relation linking certain more fundamental entities to certain less fundamental entities which derive their existence from them (Schaffer, 2016, 145). Grounding is thus the name of this direct 'linkage' which is governed by the above formal and modal principles, connects the more to the less fundamental entities and thereby imposes a bierarchical structure over what there is (Schaffer, 2009a). Now, closely related to ground's ability to structure reality are two further roles that it serves: its explanatory and generative roles, which are captured by the following principles:

(15) (Separatism) If $x$ grounds $y, x$ backs an explanation for $y$.

(16) (Super-Internality) If $x$ grounds $y$, then $y$ exists and has its intrinsic nature in-virtue of $x$ and $R x y$ obtains in-virtue of $x$.

First, for the explanatory principle of 'separatism', 17 explanation tracks grounding, and grounding, in some sense, backs explanation. Grounding entails the explicability of the grounded on the basis of its grounds and thus serves the role of providing a synchronic metaphysical explanation for the nature and/or existence of a less fundamental entity on the basis of the nature and/or existence of another, more fundamental entity (Schaffer, 2016). Thus, the grounds provide an explanation for the grounded-grounding is thus a relation that is intimately tied to explanation. Secondly, for the generative principle of 'superinternality', grounding is super-internal in the sense that the existence and intrinsic nature of one of the relatum ensure,

17 Another view within the literature is that of 'unionism' which identifies ground with explanation. For a statement of this view, see (Raven, 2015, 326) and (Maurin, 2019, 1578).

Manuscrito - Rev. Int. Fil. Campinas, v. 44, n. 4, pp. 93-168, Oct.-Dec. 2021. 
firstly, that the grounding relation obtains and, secondly, that the other relatum (or relata) exists with the intrinsic nature that it has (Schaffer, 2016).18 Thus, as there is a generation of the grounded from the grounds, once there is a fixing of the intrinsic nature of the grounds, there is also a fixing of the intrinsic nature of what is grounded. This emphasises the fact that the existence of the grounds is sufficient to account for the grounded-grounding is thus a relation that is generative by nature.

Consequently, given the fulfilment of these explanatory and generative roles, grounding thus provides the direction and linkage needed for metaphysical explanation and generation in a manner that is similar to way in which causation provides the direction and linkage needed for causal explanation and generation. More specifically, we can say that as the relation of causation links the world across time (i.e. causes are diachronically linked to their 'generated' effects), ${ }^{19}$ the relation of grounding links the world across levels (i.e. grounds are synchronically linked to the 'generated' (grounded) effects) (Schaffer, 2016). Thus, as a directeddependency relation, grounding has many important features in common with causation, which leads one to infer that the best explanation of this striking similarity is that of grounding being a type of causation: metaphysical causation (i.e. Grounding

18 That grounding is super-internal was first posited by (Bennett, 2011, 32-33). Furthermore, grounding's super-internality is not to be confused with the internality of other relations. As the former type of internality, and not the latter, requires that only one of the relatum exists in order for the relation to hold between the relata.

19 This view of causation assumes an intimate link between causation and laws of nature. For an alternative view that posits the possibility of scientific explanation/causation being expressed without laws of nature, see (Swinburne, 2004, 34).

Manuscrito - Rev. Int. Fil. Campinas, v. 44, n. 4, pp. 93-168, Oct.-Dec. 2021. 
is identical to metaphysical causation). That is, following Alastair Wilson (2018), ${ }^{20}$ we can take the grounding relation to be a special case of the causal relation where, as Wilson (2018, 724) notes, 'whenever A grounds B, A is a (metaphysical) cause of B and B is a (metaphysical) effect of A'. Metaphysical causation and nomological causation, are thus different species of the same genus: causation, such that, for the former, once one (again) distinguishes the more from the less fundamental, it is quite natural to posit an explanatorilybacking, generative relation of metaphysical causation, which leads us to the following final principle:

(17) (Causation) If $x$ grounds $y$, then $x$ causes $y$ such that $y$ is a generated 'effect' of $x$, as mediated by the principles of grounding and aptly modelled by Structural Equation Modelling.

The systematic analogy between grounding (i.e. metaphysical causation) and causation (i.e. nomological causation) centres on the manner in which the causal sufficiency relation is mediated within a causal and grounding context. More precisely, if laws of nature mediate a given instance of the causal sufficiency relation, then it is a case of nomological causation-for example, the throwing of a stone is a sufficient nomological cause of the breaking of a window, as this causal relation is mediated by laws of nature. Whereas if the (law-like) principles

${ }^{20}$ In following Wilson in taking grounding to be identical to causation-metaphysical causation-we part ways with Schaffer who takes grounding to be analogous to, but distinct from, causation. For the reasons why Schaffer does not make this identification, see (Schaffer, 2016, 94-96). And for a summary of reasons why someone should make this identification, see (Wilson, 2018, 748).

Manuscrito - Rev. Int. Fil. Campinas, v. 44, n. 4, pp. 93-168, Oct.-Dec. 2021. 
of grounding fulfil the role of mediating a given instance of the causal sufficiency relation, then it is a case of metaphysical causation-for example, the existence of Socrates is a sufficient metaphysical cause of the existence of SingletonSocrates, as this causal relation is mediated by the (law-like) principles of grounding. ${ }^{21}$ Grounding (i.e. metaphysical causation) and nomological causation are thus simply different ways for the causal relation to be mediated and thus obtain (Wilson, 2018).

Now, this species similarity between grounding and causation can be further elucidated through the use of the prominent formal framework of Structural Equation Models, which were developed within a causal context by individuals such as Judea Pearl (2009) and James Woodward (2003).22 The primary advantage of Structural Equation Models, according to Schaffer $(2016,60)$, is that of them providing the most precise method for detailing directed-dependency relationships between entities. Hence, in a directeddependency relationship, we have the sources (i.e. causes, grounds) via a link (i.e. causal law, grounding principle) generating a result (i.e. effect, derivative) which can be aptly modelled by the input-function-output structure of Structural Equation Modelling (Schaffer, 2021, 176). Thus, taking

21 Wilson (2018, 1-2) is more instructive than Schaffer (2016) in highlighting the importance of the different ways that the directeddependency relation is mediated. Furthermore, Schaffer $(2016,57)$ uses the terms 'laws of metaphysics' rather than 'principles of grounding' (or 'grounding principles') which feature in a later article (Schaffer, 2021). We can thus take both of these terms to be synonymous and in continue using the latter.

22 Though more limited than Structural Equation Models, directed graphs are also helpful in modelling directed-dependency relations. For an explanation of this, see (Schaffer, 2016, 63).

Manuscrito - Rev. Int. Fil. Campinas, v. 44, n. 4, pp. 93-168, Oct.-Dec. 2021. 
(Paradigm) as a grounding test case, in the first stage, a Structural Equation Model starts with a representation of the system under study, which is then divided into sets of independent and dependent variables. The independent and dependent variables (in this case, Socrates and Singleton) are then mapped to a specific range of allotted values as such:

$$
\begin{aligned}
V \text { ariables: }< & \text { Independents }=\{(\text { Socrates })\}, \\
& \text { Dependents }=\{\text { (Singleton })\}, \\
& \text { Range }=\{(\text { Singleton }) \rightarrow\{0,1\}, \\
& \text { (Socrates }) \rightarrow\{0,1\}\} .
\end{aligned}
$$

In the second stage, one then implements the functions given the 'dynamics' of the system, where, according to (Schaffer, $2021,177)$, there is a linking of the dependent variables by the function that maps the values of the input variables to their output value (where ' $\angle=$ ' is to be read as 'is the output of' (i.e. 'Singleton is the output of the set-formation function on Socrates'):

Functions: $\{($ Singleton $)<=$ set-formation(Socrates) $\}$. Finally, in the last stage, one simply needs to evaluate the 'fundamentality conditions', 23 by assigning values to the independent variables according to what actually happened in reality:

Assignment: $\{$ (Socrates $)=1\}$.

By $\{$ (Socrates $)=1\}$ being the case in reality, one can derive the result of $\{($ Singleton $)=1\}$ for the respective model. Utilising a Structural Equation Model in this way enables one to ascertain a viable synchronic metaphysical explanation for why Singleton Socrates exists, from the existence of Socrates,

23 In a causal model these conditions would be the initial conditions, rather than the fundamentality conditions that are featured in a grounding model.

Manuscrito - Rev. Int. Fil. Campinas, v. 44, n. 4, pp. 93-168, Oct.-Dec. 2021. 
via the dependence function that captures the grounding principles (or more specifically, the set-formation principle). ${ }^{24}$ That is, given that Socrates exists (Socrates=1) and the principles of grounding (set-formation) are at work, it is no coincidence that the Singleton-Socrates exists as well (Singleton=1). Singleton-Socrates is the output of this principle on the input of Singleton ((Singleton) $<=$ setformation(Socrates)), leading to an explanation for Singleton Socrates' existence (Schaffer, 2021). Thus, a Structural Equation Model expresses how grounding, as a metaphysical causation relation, provides the directed connection needed for explanation and induces a hierarchical structural relationship that stems from a more fundamental source (e.g. Socrates's existence) via a link (e.g. the set-formation principle) to a generated, less fundamental result (SingletonSocrates' existence). Therefore, in a grounding relationship, the more fundamental input generates and provides an explanation for the less fundamental output analogously to how a (nomological) cause generates an effect and provides an explanation for its occurrence-grounding is thus a metaphysical causation relation. 25

Given this construal of grounding, as a directed, necessitating, generative and explanatory metaphysical causation relation, we can now further elucidate the notion of fundamentality in light of this concept, and restate (Fundamentality) in its indexed format as such:

24 The set-formation principle would be a specific application of the grounding principles within a set-theoretic context.

${ }^{25}$ For brevity's sake, I will now no longer refer to grounding as metaphysical causation and simply assume that grounding within this framework is to be identified as a (metaphysical) causal relation. 
(18) (Fundamental $\mathrm{G}_{\mathrm{G}}$ ) $x$ is fundamental if $x$ is independent $_{\mathrm{G}}$ and complete $_{\mathrm{G}}$.

In unpacking this, we, firstly, can state the indexed version of (Independence) as such:

(19) (Independence ${ }_{\mathrm{G}}$ ) $x$ is independent if nothing grounds $x$.

And, secondly, we can state the indexed version of (Completeness) also as such:

(20) $\left(\right.$ Completeness $\left._{\mathrm{G}}\right)$ The set of the $x x s$ is (or the $x \times s$ plurally are, or a non-set-like $x$ is) complete at a world $w$ just in case its members ground everything else at $w$.

According to (Fundamentality ${ }_{G}$ ), as further elucidated by (Independence $\left._{\mathrm{G}}\right)$ and $\left(\right.$ Completeness $\left._{\mathrm{G}}\right)$, an entity is fundamental if it is ungrounded (i.e. not grounded by any other entity) and is a member of a set of entities at a world whose members ground everything else in that specific world. Whereas an entity is derivative, that is nonfundamental (i.e. dependent and non-complete), if something grounds it and/or it is not a member of a set of entities at a world whose members ground everything else in that specific world. ${ }^{26}$ In further precisifying this connection between fundamentality and grounding, we can apply the various grounding principles within this framework resulting in the nature of a fundamental entity being as follows:

${ }^{26}$ For brevity, the additional clause 'in that specific world' will now be an unwritten assumption.

Manuscrito - Rev. Int. Fil. Campinas, v. 44, n. 4, pp. 93-168, Oct.-Dec. 2021. 


\begin{tabular}{|c|c|c|}
\hline $\begin{array}{l}\text { Fundamentality } \\
\text { (Grounding) } \\
\text { Principles }\end{array}$ & $\begin{array}{l}\text { Independent }_{G} \\
\text { (Ungrounded) }\end{array}$ & Complete $_{\mathrm{G}}$ (Ground) \\
\hline Directed & $\begin{array}{l}\text { This entity does not } \\
\text { rank below any other } \\
\text { entity in the } \\
\text { hierarchical } \\
\text { structure of reality. }\end{array}$ & $\begin{array}{l}\text { This entity is part of a set that ranks } \\
\text { higher than any other entity in the } \\
\text { hierarchical structure of reality } \\
\text { within the specific world in which } \\
\text { this set exists. }\end{array}$ \\
\hline Necessitating & $\begin{array}{l}\text { The existence of } \\
\text { another entity does } \\
\text { not necessitate the } \\
\text { existence of this } \\
\text { entity. }\end{array}$ & $\begin{array}{l}\text { This entity is part of a set that } \\
\text { necessitates the existence of every } \\
\text { other entity within the specific } \\
\text { world in which this set exists. }\end{array}$ \\
\hline Generative & $\begin{array}{l}\text { This entity's } \\
\text { existence and } \\
\text { intrinsic nature are } \\
\text { not fixed by the } \\
\text { existence and } \\
\text { intrinsic nature of } \\
\text { any other entity. }\end{array}$ & $\begin{array}{l}\text { This entity is part of a set whose } \\
\text { existence fixes the existence and } \\
\text { intrinsic nature of every other entity } \\
\text { within the specific world in which } \\
\text { this set exists. }\end{array}$ \\
\hline Explanatory & $\begin{array}{l}\text { This entity's } \\
\text { existence, at a } \\
\text { specific time, is not } \\
\text { explained by the } \\
\text { existence of any } \\
\text { other entity. }\end{array}$ & $\begin{array}{l}\text { This entity is part of a set that, at a } \\
\text { specific time, explains the existence } \\
\text { of all other entities within the } \\
\text { specific world in which this set } \\
\text { exists. }\end{array}$ \\
\hline Causal & $\begin{array}{l}\text { This entity is not a } \\
\text { grounded effect of } \\
\text { any other entity and } \\
\text { thus is not the } \\
\text { output of a } \\
\text { Structural Equation } \\
\text { Model. }\end{array}$ & $\begin{array}{l}\text { This entity is part of a set that is the } \\
\text { metaphysical cause of other entities, } \\
\text { which are grounded effects, and } \\
\text { thus is the input of a Structural } \\
\text { Equation Model within the specific } \\
\text { world in which this set exists. }\end{array}$ \\
\hline
\end{tabular}

\section{Table 1. 1 Fundamentality Principles}


A fundamental entity is thus one that is not an output of a grounding relation; rather, it ultimately serves as the ground of everything else. For a fundamental entity, nothing presses upwards on it; instead, it serves the role of pressing upwards on all other (non-fundamental) entities - it is a basic feature of the hierarchical structure of reality (Bennett, 2017, 111).

Closely related to the notion of absolute fundamentality just detailed is that of the further notion of relative fundamentality. Relative fundamentality, according to Bennett $(2017,40)$, is best characterised, like absolute fundamentality, in terms of building. That is, relative fundamentality lacks metaphysical depth through being nothing over and above patterns of building - it is a notion that is reducible to building and the various relations that constitute this resemblance class. Given this reduction (or deflation), one can thus, as Bennett $(2017,164)$ notes, provide conditions for the notion of relative fundamentality which, indexed to the building relation of grounding, can be stated as such:

(21) (More

Fundamental

Than) $x$ is

more

fundamental

than $y=\mathrm{df}$

either (i) fewer grounding steps from an ungrounded entity than $y$ is, or

(ii) $x$ at least partially grounds $y$, or

(iii) $x$ stands in the ancestral of a grounding relation to $y$, or

(iv) $x$ is ungrounded and $y$ is not, or

(v) $x$ belongs to some kind $\mathrm{K}$ and $y$ belongs to some kind $\mathrm{K}^{*}$ such that (a) neither $\mathrm{K}$ nor $\mathrm{K}^{*}$ includes both grounded and ungrounded members, and (b) $y$ does not belong to $\mathrm{K}$ and $x$ does not belong to $\mathrm{K}^{*}$, and (c) members of $\mathrm{K}$ typically or normally ground members of $\mathrm{K}^{*}$. 
These five sufficient conditions of relative fundamentality are to be viewed as a disjunction where an entity can be more fundamental than another entity through satisfying any of the above conditions. Thus, focusing on (ii), any entity that is in (at least a partial) grounding relationship with another entity is more fundamental than that entity - that is, if one thing grounds another, then the former thing is more fundamental than the latter. Grounds are more fundamental than what they ground. Hence, for an entity to be more fundamental than another entity is simply for it to fulfil the role of being that entity's (partial) grounds. Taking these two notions of fundamentality into account, we can now further precisify the layered structure of reality introduced earlier.

\subsection{Metaphysical Foundationalism}

Reality is hierarchically arranged with chains of entities being ordered by the building relations of grounding. And thus, the entities in this hierarchical structure that are taken to be the input of these grounding relations are more fundamental than the entities that are taken to be the output of these relations. These grounding chains, according to this metaphysical picture-termed metaphysical foundationalismterminates in something(s) that is itself absolutely fundamental. ${ }^{27}$ So, with the (building based) notions of absolute and relative fundamentality to hand, we can slot this

27 The thesis of metaphysical foundationalism is sometimes mistakenly confused with the more controversial notion of the well-foundedness of grounding. For an explanation of the latter and the importance of distinguishing both notions, see (Dixon, 2016) and (Rabin and Rabern, 2016).

Manuscrito - Rev. Int. Fil. Campinas, v. 44, n. 4, pp. 93-168, Oct.-Dec. 2021. 
notion into the layered conception of reality detailed above, which will result in the following structure:

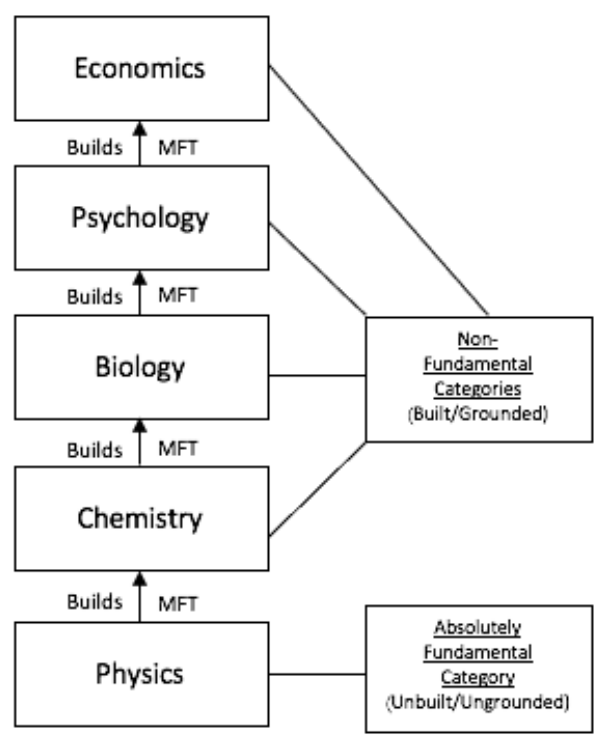

\section{Fig 1. 1 Layered Structure of Reality}

This is the content and structure of reality, but the important question for our specific task is: why do any of these entities exist rather than not? A quick and easy answer would be that each of these entities exists in virtue of the entities that are more fundamental than them-that is, they exist because of the lower-level entities grounding their existence. This is indeed a sufficient explanation, as the existence of the lowerlevel entities, and the holding of the relation of grounding, necessitates the existence of the higher-level entities. So with each level that we descend, plausibly, we have a full 
metaphysical explanation that is provided by a more fundamental entity at a lower level. For example, the existence of a given human being is grounded by the existence of their more fundamental chemical states, and the existence of their more fundamental chemical states are, in turn, grounded by some more fundamental quarks, which are then taken to exist as absolutely fundamental entities- they are independent and complete. So, we have a full metaphysical explanation being provided within this chainthat is, the existence of each of the entities in this chain has really been explained. Yet, despite having this type of explanation for each of the entities along this chain, one can ask why the terminus in explanation should stop there? Why can we not go beyond the constitutive quarks of the human being to something more fundamental and then continue proceeding on downwards potentially ad infinitum? In short, why must we posit the existence of an absolutely fundamental entity that serves the role of being a terminus of explanation? Instead of holding to some form of metaphysical infinitism — resulting in the reality being 'turtles all the way down'?28 Well, why we seemingly must do this is because, despite having an explanation for each of the entities along this chain, what we do not have, as Ricki Bliss (2019, 370-373), has noted in a similar context, is that of an explanation for why there are any non-fundamental entities whatsoever. That is, given that a non-fundamental entity is, by definition, a dependent entity, we seem to require an explanation for it existing rather than not existing. And simply invoking a more fundamental entity than the one that is under focus (e.g. the chemical state and quarks for the

${ }^{28}$ Metaphysical infinitism is the view that are, or might be, infinitely descending chains of grounding, for a further explanation and defense of this view, see (Morganti, 2014).

Manuscrito - Rev. Int. Fil. Campinas, v. 44, n. 4, pp. 93-168, Oct.-Dec. 2021. 
existence of a given human) does not provide the needed explanation, so long as the more fundamental entities in the chain are themselves non-fundamental. Our explanatory target - the fact that there are any non-fundamental entities whatsoever-is in need of an explanation. Yet, no nonfundamental entity can explain why there are any nonfundamental entities whatsoever-none of these entities is adequate for the task at hand. And this inadequacy is seen quite clearly with the holding of what Bliss $(2019,373)$ terms, the kind-instantiation principle, ${ }^{29}$ which is stated as follows:

(22) (Kind Instantiation) Where $\mathrm{K}$ is any substantial kind, you can't explain why there are any Ks at all by invoking only $\mathrm{Ks}$, even if our explanation goes on forever.

Given the kind-instantiation principle, and taking 'nonfundamental entity' to be a substantial kind, one cannot thus explain why there are any non-fundamental entities, rather than none, by invoking only non-fundamental entities, even if one's explanation goes on forever. That is, as no member of a kind can explain why that kind is instantiated in the first place, one must move beyond the collection of non-fundamental entities in order to explain why there are non-fundamental entities

${ }^{29}$ The following principle assumes a 'weak' version of the Principle of Sufficient Reason (PSR), such as one stated by Bliss $(2019,375)$ that is saddled to dependence:

(PSR) Every dependent fact has an explanation.

For the specific reasons for and against this particular construal of the PSR, see (Bliss, 2019, 374-376).

Manuscrito - Rev. Int. Fil. Campinas, v. 44, n. 4, pp. 93-168, Oct.-Dec. 2021. 
whatsoever. We thus require a terminus in explanation to account for the existence of non-fundamental entities, which is itself inexplicable and thus is not a dependent link within the explanatory chain of the hierarchical structure of reality. In short, the explanatory target noted above-of there existing non-fundamental entities, rather than none at allseeks an explanation provided by the existence of an absolutely fundamental entity (or entities).

Now, as noted above, there are at least two possible kinds of fundamental explanation: inanimate fundamental explanation and personal fundamental explanation. Candidate explanations that fall into either of these kinds will need to be assessed by the inductive criteria for assessing proposed explanations that was introduced in the previous section. Importantly, however, when one is considering explanations of the existence of all of the non-fundamental entities that feature in the layered structure of reality, each of these hypotheses will be of enormous scope. Therefore, unless we are to dismiss these and all other potential fundamental explanations, Criterion (iii) will need to be left out of our assessment. Thus, any candidate fundamental explanation under question will need to be assessed by Criterion (i), (ii) and (iv), which boils down to a candidate for a fundamental explanation, in this specific context, being most likely the true one, if it is the simplest explanation, fitting with our background knowledge, which predicts the existence of non-fundamental entities, when we would not otherwise expect to find them. Given this framework and our exposition of our explanatory target, it will be important to now turn our attention to unpacking the inanimate and personal explanatory candidates for a fundamental explanation, and then, off of this, we can make an assessment of which one, according to our inductive criteria, deserves to be crowned as the fundamental explanation that the human quest for knowledge has been seeking. 


\section{Explanatory Analysis}

\subsection{Nature of the Candidates}

In contemporary metaphysics, three candidates for a fundamental explanation for our explanatory target present themselves: Theism, Priority Monism and Priority Pluralism. For the latter two: Priority Monism and Priority Pluralism—each of which is a candidate inanimate fundamental explanation-we have two physics-based explanations that support the commonly held view that whatever is at the fundamental layer of reality, and thus is the terminus in explanation for everything above (or below it), is of a physical nature-in short, everything bottoms out at the feet of a physical entity (or entities). Whereas, for the former: Theism-which is a candidate personal fundamental explanation - we have a theologically-based explanation that supports a view that the fundamental layer of reality, and terminus in explanation for everything above (or below it), is of a non-physical nature-in short, everything bottoms out at the feet of a non-physical fundamental entity. So, these are the three candidate explanations of the existence for the various non-fundamental entities that fill up the levels of our layered structure of reality. And thus it these candidate fundamental explanations that will need be assessed for their veracity according to our inductive criteria. However, prior to performing this assessment, it will be helpful to now briefly detail the nature of the entities that are posited by these explanations. We can turn our attention first to that of Theism and then after this we can focus on the other two alternative candidates.

The theistic explanation centres around the simple claim that 'there is a God'. This claim is a personal metaphysical explanation-it seeks to provide an explanation that invokes the powers, beliefs and intentions of a personal agent—and 
it is a claim that is at the heart of the major theistic world religions such as: Judaism, Christianity, Islam and Sikhism. Now, there are various ways to construe this particular claim; however, the specific way that it will be construed here is as follows: 30

(23) (Theism) There is a God: a metaphysically simple, omnipotence-trope.

This specific rendering of Theism centres around the notion of a 'powerful trope'-a powerful abstract particular nature of a modifier or modular kind-which has been introduced and defended by various 'trope theorists' such as D.C. Williams (1953), Keith Campbell (1990), Anna Sofia-Maurin (2002) and George Molnar (2003), among others. In breaking this concept down in a stepwise manner, we can understand that: first, a trope is abstract, not in the sense that it lacks spatiotemporality, but in the sense that it is 'less than its

${ }^{30}$ In Swinburne's (2004, 93-96) conception of theism, God is, amongst other things, an essentially, everlastingly omnipotent, bodiless spirit. This conception of God has been challenged by individuals such as Herman Philipse $(2012,205)$ who argues that the notion of a bodiless spirit fails to fit with our background knowledge concerning the type of entities that are taken to exist in neighbouring fields. Given this issue, Criterion (ii) is not met by Swinburne's conception of Theism. However, as explained previously, Swinburne $(2004,66)$ does not see Criterion (ii) as being overly important for explanations of a wide explanatory scope, and thus does not see this to be a problem. Nonetheless, the present construal of God does not succumb to this issue, given the widely held assumption amongst philosophers concerning the existence of tropes, and thus Criterion (ii) can be met by Theism so construed. This widely held assumption will be further explained below. 
content' and does not 'exhaust its plime'-in short, multiple tropes can be co-located together to form a compresent bundle. For example, a shape-trope that a table possesses is abstract because it does not exhaust its content, as other tropes, such as a colour-trope and a mass-trope, are also collocated with the shape-trope by occupying the same content (i.e. the table). However, in contrast, the table would be concrete by itself exhausting its content and thus not allowing another table (or object) to also occupy this content (Williams, 1953). Second, a trope is particular in the sense that it can have a distinct duplicate-in other words, Leibniz's Law (i.e. the identity of indiscernibles) fails to hold for it. ${ }^{31}$ That is, for properties as universals, the Law holds, in that exactly similar entities (i.e. universals) are identical (i.e. if universal $\mathrm{x}$ and universal $\mathrm{y}$ are indiscernible, then $\mathrm{x}=\mathrm{y}$ ). Whereas for particulars (e.g. tropes), the principle does not hold, as exactly similar entities can be distinct (i.e. if trope $\mathrm{x}$ and trope $\mathrm{y}$ are indiscernible, then $\mathrm{x} \neq \mathrm{y}$ ). For example, a shape-trope is particular because it is possible that there is a duplicate of this shape, that is, an entity that is exactly similar, but also distinct from this shape. In short, a trope is particular if it can have a duplicate. Third, a trope is its intrinsic (qualitative) nature, in that it does not have, or possess, a nature of its own; rather, it is combinatorially intrinsic in the sense that the nature of a trope is invariant under the scenarios in which the given trope is alone or accompanied (Alvarado, 2019, 554). However, the modal invariance of a trope, unlike other entities, is not grounded upon the possession of an intrinsic nature, but that of it being its

${ }^{31}$ Leibniz's Law, which is often conceptualised as the principle of the indiscernibility of identicals, is conceived of here as its converse- the principle of the identity of indiscernibles, which can be stated formally as such: $\forall \varphi(\varphi(x) \leftrightarrow \varphi(y) \rightarrow x=y)$. 
intrinsic nature-it is numerically identical to it. There is nothing more to a trope than its nature, and thus, as noted by Anna-Sofia Maurin (2018, \$2.2), tropes, at a general level, 'have no constituents, in the sense that they are not 'made up' or 'built' from entities belonging to some other category'. Tropes are thus primitively qualitative and irreducible entities-they lack proper-parts, 32 and thus are metaphysically simple entities..$^{33}$ Fourth, a trope can come in two forms: as a modifier or as a module trope. The central difference between a modifier trope and a module trope is that of the former being a singly (or minimally) characterising property, whilst the latter is a singly (or minimally) charactered property in a 'stretched' (or analogical) sense- it is a 'propertied thing or object', where an object is a countable, property-bearing particular that has determinate existence and identity conditions and is not borne or possessed by anything else. ${ }^{34}$ In other words, a modifier trope is a property that does not exemplify this character, but simply bestows it upon (i.e. 'makes') something else to be charactered in that specific way. Thus, for example, a particular object is spherical in virtue of its modifier trope, which 'spherises' that object by simply making it spherical without it sharing in that character as well. The character grounding provided by a modifier trope is thus de novo (or sui generis) (Garcia, 2015a). Whilst, a module trope is an object that exemplifies the character that it grounds (i.e. is self-exemplifying). Thus, for example, a particular (thickly-charactered) object is spherical and red in virtue of its module tropes, which are themselves spherical and red (i.e. exemplify sphericity and redness), and

32 More on the nature of a proper part below.

33 More on the nature of metaphysical simplicity below.

${ }^{34}$ I leave the account of analogy here undefined.

Manuscrito - Rev. Int. Fil. Campinas, v. 44, n. 4, pp. 93-168, Oct.-Dec. 2021. 
together (compresently) are parts (or constituents) of that object. A module tropes' character grounding, rather than being de novo, can thus be taken to be some type of parthood (or constitution) relation (Garcia, 2015a). Furthermore, an additional distinction between modifier and module tropes is the role played by these types of tropes in causation. At a more specific level, it is solely module tropes, rather than modifier tropes, that can play any direct role in causation. As, for example, a modifier hotness trope cannot fulfil the role of being the direct cause of a burn mark that an individual has, as it is not itself hot; something else must thus be the direct cause of the burn mark (Garcia, 2015a, 643. Modifier tropes, in a similar manner to universals, are thus causally inert. However, the modular view does not have this issue, given that module tropes are self-exemplifying entities, resulting, in our example above, in a modular hotness trope being able to be the direct cause of the burn mark. Therefore, it is module tropes, and not modifier tropes, that are uniquely suited to be the basic terms of causation (Garcia, 2015a). Lastly, a trope, following Molnar (2003), is powerful in at least five ways: it is, first, directed - in that a powerful trope is directed towards some characteristic and distinctive manifestation. ${ }^{35}$ Second, it is independent-in that a powerful trope is ontologically independent from its manifestations, that is, it can exist when it is not being manifested. Third, it is actual -in that a powerful trope is an occurrent feature of the object that possesses it. Fourth, it is intrinsic - in that a powerful trope is intrinsic to its bearer. ${ }^{36} \mathrm{Fifth}$, it is objectivein that the existence of a powerful trope is not dependent on the existence of any conscious, observing minds. A trope, of

${ }^{35}$ An assumption is made here concerning a powerful trope being multi-track, rather than single-track.

${ }^{36}$ We can assume the notion of intrinsicality noted above. 
a modifier or modular kind, is thus powerful in that it fulfils the roles of directedness, independence, actuality, intrinsicality and objectivity.

Taking this concept of a powerful module trope into account, and applying it within a theistic context, we can posit that God is, first, abstract in the sense of him having the trait of being 'less than the including whole'-God does not exhaust his 'content' or 'plime' (or is less than his 'content' or 'plime' ) — where, in assuming Christian Theism, we take this content or plime to be the Trinity as a whole and its location-as its content or plime also includes the possibility of other tropes being collocated with him (i.e. the Son and the Spirit), which results in him not exhausting either of these things-in short, wherever God is located there are other tropes that are located there with him. Second, God is particular by him failing to abide by Leibniz's Law-as, in assuming Christian Theism again — there is the possibility of the existence of entities-duplicates, identified as the Son and the Spirit - that are exactly similar in their intrinsic properties (i.e. their nature) to him, yet are numerically distinct from him. Third, God is identical to his qualitative nature- he is the specific character that he has, which is that of him being omnipotent. God's nature is thus intrinsic to him, not in the sense of him possessing a further intrinsic 'property', but simply that of him being numerically identical to this nature. Fourth, God is a module trope, rather than a modifier trope, which is that of him being a maximally-thinly charactered object-a property in an analogous sense (i.e. a property*) — that is self-exemplifying and, in assuming Christian Theism again, serves the role of bestowing this characteristic upon the Trinity which he constitutes. Moreover, since God is a trope of a modular kind, he plays a direct role in causation and is thus a basic term of a causal relation. Lastly, as a module trope, God is powerful in five ways: he is, first, directed - in that God (or 
his action) is directed towards some characteristic and distinctive manifestations, such as that of creating or sustaining the universe. Second, he is independent-in that God is ontologically independent from his manifestations, that is, he exists when his power is not manifested. ${ }^{37}$ Third, he is actual-in that God is an occurrent feature of the object that possesses him: the Trinity. Fourth, he is intrinsic — God is intrinsic to his bearer, which is, again, the Trinity. ${ }^{38}$ Fifth, he is objective - in that the existence of God is not dependent upon the existence of any conscious, observing minds. God, as a module trope is thus powerful in that he fulfils the roles

37 Though in the grounding of the non-fundamental entities that fill up the layered structure of reality, God's power will not move from inactivity to activity, but, instead, would always be manifested, given that this grounding act will be a necessary action that stems from God's perfect goodness. More on this below.

38 As Christian Theism is being assumed here, God is taken to be a 'part' of the Trinity and thus is borne by, and works through, the Trinity (i.e. in cooperation with the Son and the Spirit). This conception of the Trinity assumes the notion of the "monarchy of the Father'- the teaching that God is numerically identical to the Father alone-which is contrary to the common position that holds to God being numerically identical to the Trinity. The difference between these positions is more than a linguistic issue as proponents of the monarchy of the Father will take the existence of the Father to be the basis for Christian Theism being monotheistic_as there is 'one Father' there is 'one God'whereas proponents of the common position would take the existence of the Trinity to be the basis for Christian Theism being monotheistic — the 'unified collective' (i.e. the Trinity) is the 'one God'. For a further philosophical explication of the notion of the monarchy of the Father and its application to the Trinity, see (Sijuwade, 2021b). 
of directedness, independence, actuality, intrinsicality and objectivity. However, he does this without any of the limitations that certain other powerful module tropes may have. In short, God is an unlimited powerful trope-an omnipotencetrope, which can be illustrated as such:

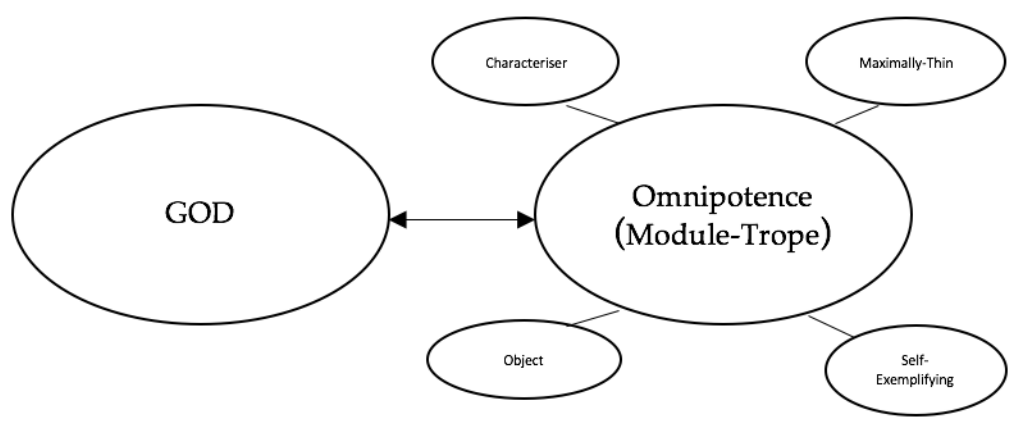

Fig 1. 2 God and Module Trope Identity

As an omnipotence-trope, God is a personal entity-a personal module trope-due to the fact that for him to exercise his omnipotence, he must be an entity that has a rich form of consciousness that enables him to perform a range of actions that are solely limited by logic. Thus, to ward off a potential objection that can be raised here, conceiving of God as a trope does not rob him of this personhood, given that he is a trope of a modular nature (i.e. a property*). Furthermore, given his omnipotence, God would be an entity that is unlimited in knowledge, presence, freedom and goodness. That is, it follows from his omnipotence that God would, firstly, be omniscient-he would know of all true propositions (concerning the past and present), that they are true-as, if he is to be able to exercise his omnipotence, he 
would need to know the nature of the alternative actions that are dependent upon what occurred in the past and what is presently occurring. Secondly, being omnipotent and also omniscient, God would be omnipresent-he would be cognizant of, and causally active at, every point of spaceand thus would be present to all existing things through his knowledge concerning them and his power to act upon them. Thirdly, being an omnipotence-trope, he would also be perfectly free-he would be free from any non-rational influence determining the choices that he makes - as if he is to be able to exercise his power in any logically possible way, then his power must operate without any causal limitation or hindrance. Fourthly, being omniscient and perfectly free, God would also be perfectly good - he will always perform the best action (or kind of action) if there is one, many good actions and no bad actions. That is, given God's omniscience, he would know the nature of each available action that he can choose from and thus would possess knowledge of whether each action is good or bad, or is better than some incompatible action. Moreover, in recognising an action as good, God would have some motivation to perform that action, and in recognising an action as being better than another action, God would have an even greater motivation to perform it (Swinburne, 2016). Hence, given his perfect freedom, if God is situated in a scenario in which there is a best possible action (or best kind of action) for him to perform, then God will always perform that action (or kind of action), and if there is no best action (or kind of action), then God will perform a good action and no bad actions. ${ }^{39}$.

39 Whereas in recognising an action as bad, God would have no motivation to perform it 
These are the attributes-omniscience, omnipresence, perfect freedom and perfect goodness-that are derivable from the supposition that God is an omnipotence-trope. However, in construing God as a module-trope, we can also take him to be metaphysically simple, given the non-composite and irreducibility of a trope. And so, in conceptualising God in this particular way, we can see that the derivable attributes of God-unlike Swinburne, who takes these attributes to be related to God (and each other) by an 'entailment relation'are in fact related to God (and each other) by a relation of 'numerical identity'. ${ }^{40}$ More specifically, according to the notion of metaphysical simplicity, God is non-composite and irreducible in the sense of him lacking proper partswhere a proper part is a portion of an entity that is numerically distinct from it. Thus, by taking God to be metaphysically simple, there is no portion of God that is numerically distinct from him. God is a being who intrinsically within himself does not have any division or

40 Specifically, these entities are conceived of as 'aspects'qualitative differing, yet numerically identical particular ways that an entity is. Construing these entities in this way enables the primary objections against the cogency of the notion of metaphysical simplicity to be put to rest-as God is taken to bear (qualitatively differing) 'divine aspects', rather than 'divine properties', which enables God's power, knowledge, goodness etc., to be numerically identical to him and each other-as aspects are numerically identical to their bearers and one another-whist still maintaining a qualitative distinction between them-as aspects qualitatively differ from their bearers and one another. God thus has multiple, qualitatively differing aspects that are 'improper parts' of him (i.e. numerically identical to God) rather than 'proper parts' of him (i.e. numerically distinct from God). For reasons of space, this account will not be further detailed. However, for a further explanation of this account, see (Sijuwade, 2021a). 
ontological composition-be it spatial, temporal or metaphysical composition-God must be such that he does not have any sort of complexity involving composition. So, the denial of metaphysical complexity in God is thus also a denial of him possessing any properties as well. More specifically, God does not exemplify any numerically distinct properties (i.e. proper metaphysical parts). Since if God were to exemplify these properties, he would be dependent upon them in order to be what he is. Yet, as God cannot be dependent in specific this way-given that he is omnipotent-he thus must not be the bearer of any properties. Rather, any intrinsic property 'attributable' to God must be numerically identical to him. For example, if the intrinsic property of goodness is attributed to God, then one is not properly attributing to him an ontologically distinct property that he exemplifies. Rather, God is instead taken to be identical with his goodness (and all the other properties that are attributed to him as well). Moreover, given that God is identical to each of his attributes, one must also infer that his attributes are identical to each other due to the transitivity of identity. Thus, God's identity with his goodness and his power entails the fact of his goodness being identical to his power (and, again, for all of the other properties that are attributed to him). Therefore, on the basis of God's metaphysical simplicity, there is, firstly, no numerical distinction between God and his attributes and, secondly, there is no numerical distinction between each of God's attributes as well, as can be seen through this illustration (where the double-headed arrows represent a numerical identity relation): 


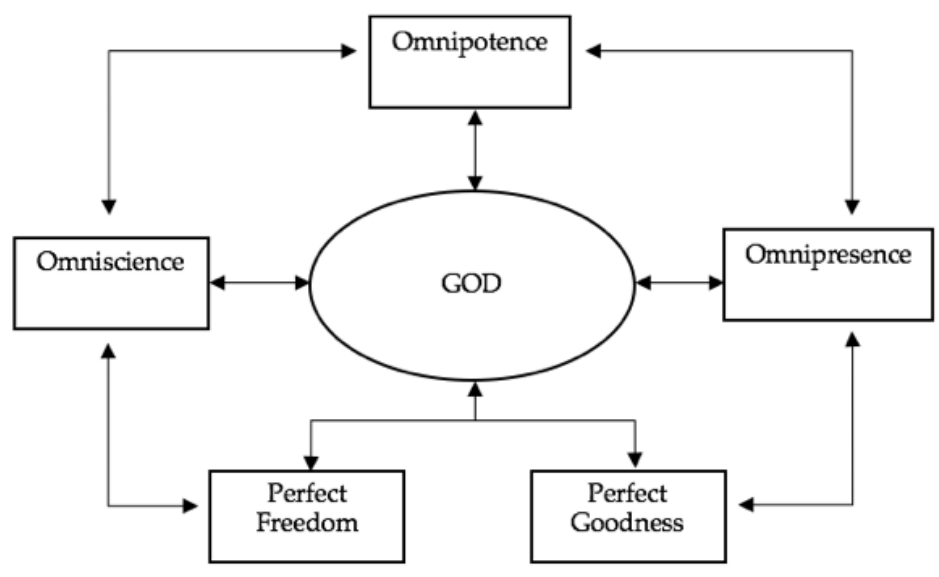

Fig 1. 3 God and Attributes Identity

Theism thus postulates the existence of one, metaphysically simple (and personal) module trope: God, who has the single character of omnipotence and is numerically identical to each of the attributes of divinity that are rightly predicated of him. So construed, God is a fundamental entity, by, on the one hand, his metaphysical simplicity rendering him as independent-his non-compositeness and irreducibility would thus not require him to be an output of a grounding relation-and, on the other hand, his omnipotence rendering him as complete - by him possessing the ability to perform any logically possible action, anything that exists will be by him willing, or permitting, it to exist. Therefore, if God exists, he is rightly understood as a metaphysically simple, omnipotence trope that exists fundamentally. We can now turn our attention to fleshing out the nature of the alternative candidate fundamental explanations of Priority Monism and Priority Pluralism. 
In the field of fundamental mereology, Jonathan Schaffer (2009a,b, 2010, 2013) has proposed a distinction between the notions of Priority Monism and Priority Pluralism. At a basic level, the priority monist holds to the whole being prior to its parts and thus takes there to be only one fundamental entity in the layered structure of reality. In contrast, the priority pluralist holds to the parts being prior to the whole and thus takes there to be more than one fundamental entity in the layered structure of reality. More precisely, according to Schaffer (2010, 33-37), there are two structures within reality: a mereological structure of whole and part and a metaphysical structure of prior and posterior. The latter type of structure: metaphysical structure, which we have been operating within, captures the fact of one entity being built by another entity, and ultimately reveals what is (or are) the fundamental entity (or entities) that serves as the builder(s) of all other reality - in short, all chains of building ultimately terminate in this entity (or entities). The debate between priority monists and pluralists, in Schaffer's (2010) thought, is thus concerning the right correlation between this mereological order of whole and part and the metaphysical order of priority and posteriority. More specifically, it concerns the identification of what is fundamental among existing concrete entities. As priority monists and pluralists both hold to there being a maximally actual concrete object-the material Cosmos_of which all other actual concrete, material objects (e.g. planets, pebbles and particles etc.) are proper parts. The assumption is thus made on both sides that there is a Cosmos, that it has proper parts and that it is not identical to any plurality of its proper parts (i.e. composition is not identity). Thus, the central distinction between these two positions centres on how to carve up the Cosmos (Schaffer, 2010, 42). Focusing first on Priority Monism, adherents of this view see the correct way to carve up the Cosmos as that of leaving the whole uncut. Thus, on this view, there is solely 
one fundamental actual concrete object: the Cosmos itself. Importantly, however, and in distinction from existence monism - the view that solely the Cosmos exists and nothing else-there are many other concrete, material objects; yet, these objects exist only in a derivative manner as proper parts of the one fundamental entity that is the Cosmos. Thus, in providing a precisification of this view, we can state the monistic position succinctly as such:

(24) (Priority Monism) The whole, identified as the Cosmos, is the single, fundamental concrete object that is ontological prior to all other actual concrete material objects, which are its proper parts.

Now, it is not built into the notion of Priority Monism that the single fundamental entity: the Cosmos, has any particular nature. Rather, the notion so characterised is strictly a numerical thesis concerning the number of fundamental entities - which, for Priority Monism, is that of there being one. However, a specific way of further detailing the nature of this fundamental entity has been provided by Schaffer (2009b). ${ }^{41}$ In this particular construal of Priority Monism, the nature of the Cosmos - the fusion of all actual concrete, material objects-is, according to Schaffer (2009b, 132-133), to be identified as the general-relativistic spacetime manifold. And material objects - the proper parts of the Cosmos-are to be identified as regions of spacetime. Thus, the spacetime manifold that is the Cosmos is a single substance that

${ }^{41}$ Thus, at a more specific level, the candidate explanation that will be assessed below is the more robust version provided by Schaffer-rather than a more bare-bones version of Priority Monism. 
instantiates properties directly - that is, without any mediation of material objects. Rather, the properties are 'pinned down' onto the spatiotemporal substance. The Cosmos thus possesses proper parts-identified as spacetime regions instantiating properties - that it is more fundamental than, which renders these proper parts as derivative and nonfundamental entities that depend upon the Cosmos for their existence.

Turning our attention to Priority Pluralism, adherents of this view see the correct way to carve up the Cosmos as that of cutting it up into smallerpieces. Specifically, this position of Priority Pluralism is a conjunction of the numerical thesis concerning how many fundamental entities there are-there being at least two fundamental entities - and the partialistic thesis that the Cosmos is non-fundamental (Schaffer, 2010, 43). Thus, in providing a precisification of this view, we can state the pluralistic position succinctly as such:

(25) (Priority Pluralism) There exists many fundamental entities, which are the ontologically prior proper parts of the Cosmos and all other actual concrete objects.

Now, again, it is not built into the notion of Priority Pluralism that the numerous fundamental entities that are taken to exist have any particular nature. Rather, the notion so characterised, as with Priority Monism, is strictly a numerical thesis concerning the number of fundamental entities - which, for Priority Pluralism, is that of there being many. However, a specific way of further detailing the nature of these fundamental entities has been provided by Peter 
Simons (2020).42 This particular construal of Priority Pluralism is that of Atomism - the view in which the fundamental concrete objects are mereological atoms. Priority Pluralism, construed in this atomistic way, posits that all derivative entities - including the Cosmos — are grounded in the collection of mereological atoms - which, following Simons (2020), can be conceptualised as indivisible (pointparticle like) module tropes..$^{43}$ The fundamental layer of reality is thus an indivisible (because un-extended) collection of (point-particle like) module tropes that support the existence of all other non-fundamental entities. The Cosmos, is itself a non-fundamental entity and thus can be cut into mereologically minimal slices.

Priority Monism and Priority Pluralism, so construed, are thus exhaustive and exclusive positions due to the holding, of what Schaffer $(2018$, \$3.1) terms, the tiling constraint. The tiling constraint is the conjunction of the following two conditions (where we can take the predicate ' $\mathrm{F}$ ' to denote the property of being a fundamental concrete object, and the letter ' $u$ ' to refer to the Cosmos):

(26) (Covering) Sum: $x(F x)=u$

42 Thus, again, at a more specific level, the candidate explanation that will be assessed below is the more robust version provided by Simons-rather than a more bare-bones version of Priority Pluralism.

43 Simons does not explicitly term his account a 'priority pluralist' account, nor does he term the tropes that feature in his account 'module tropes'. However, his atomistic account is clearly one that affirms the central tenets of Priority Pluralism and, given the distinction that was made earlier between modifier and module tropes, the concept of a trope that features in Simons' account is certainly that of the latter, rather than that of the former.

Manuscrito - Rev. Int. Fil. Campinas, v. 44, n. 4, pp. 93-168, Oct.-Dec. 2021. 
(27) (No Overlap) $(\forall x)(\forall y)((\mathrm{F} x \& \mathrm{~F} y \& x \neq y) \supset \sim(\exists z)$ $\left.\left(\mathrm{P}_{2} \times \mathrm{P}_{z y}\right)\right)$.

The first condition of the tiling constraint: (Covering), expresses the requirement within fundamental mereology that the sum of all fundamental entities is the Cosmos as a whole- there is no portion of the Cosmos which is thus left uncovered. The second condition of the tiling constraint: (No Overlap), expresses the requirement that the fundamental entities are not to have any common partsthus, these entities are mereologically disjoint. The picture that is given by these two conditions is that of the fundamental entities tiling the cosmos in the sense that they partition or cover every portion of reality without them overlapping (Schaffer, 2018, \$3.1).

So, for Priority Monism, there is one and only fundamental entity: the whole Cosmos, which is prior to its proper parts-all other existing concrete entities. Whereas, for Priority Pluralism, there are many fundamental entities, each of which is a proper part of the Cosmos, identified as mereological atoms - un-extended (point particle like) module tropes. We can illustrate the position expressed by Priority Monism and Priority Pluralism as such: 


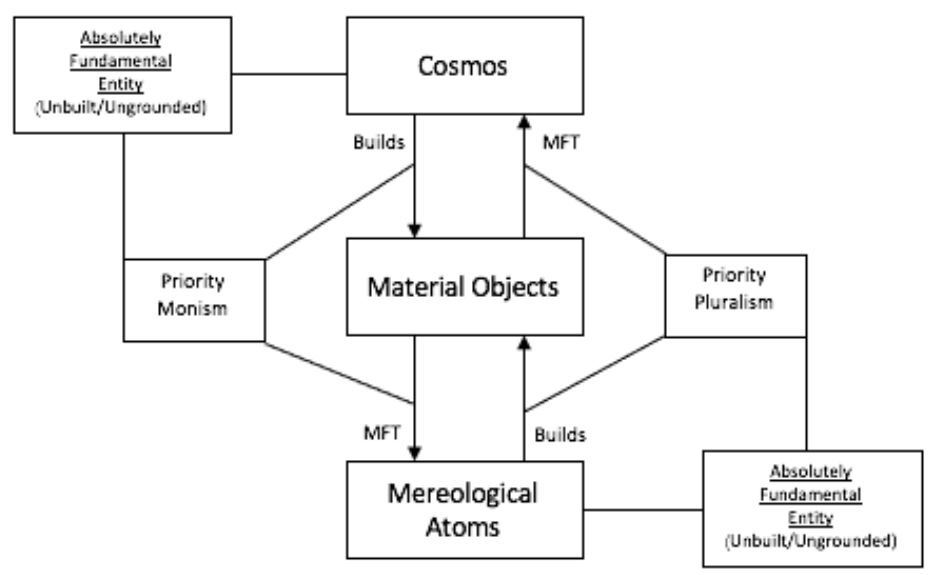

Fig 1. 4 Priority Monism and Pluralism Structure

Thus, to reiterate a key point, the primary disagreement between Priority Monism and Priority Pluralism does not concern the existence of the Cosmos, material objects or mereological atoms-these are all shared assumptions. Rather, given the tiling constraint, and the fact that Priority Monism is equivalent to $F u$-the Cosmos being a fundamental entity — and Priority Pluralism being equivalent to $\sim F u$ - the Cosmos not being a fundamental entitythese two positions are simply an exhaustive and exclusive way to carve up reality — stick with monism, and you keep fundamental reality intact and whole, or go with pluralism, and you cut fundamental reality down to its smallest pieces. Thus, the Cosmos, or the collection of mereological atoms, if they exist in the manner so construed, exist as fundamental entities - they are independent and complete - through the tiling constraint enabling them to cover all of reality. Taking all of these things into account, these are the three candidate 
fundamental explanations of our explanatory target. Now, to determine which of these options is to be deemed as the fundamental explanation and terminus in explanation for the existence of the various non-fundamental entities within the layered structure of reality, we must assess and compare the manner in which these explanations fulfil our inductive criteria. This assessment will now be done by focusing first, again, on Theism and then turning our attention to Priority Monism and Pluralism.

\subsection{Assessment of the Candidates}

Theism has predictive power, in respect to our explanatory target, to the extent to which we can attribute to God an intention to bring about the existence of nonfundamental entities. Plausibly it is the best kind of action for God to bring about these types of entities, given the unique goodness of this action. Specifically, the performance of this action is a unique good due to the holding of the Diffusiveness Principle, which can be stated as follows:

(28) (Diffusiveness) Goodness is necessarily diffusive of itself.

At a general level, according to the Diffusiveness Principle, goodness requires something other than itself as a manifestation of itself. Hence, a good being will inevitably bring about other good things. Thus, as it is better to exist than not to exist-existence is a good thing-God, as Norman Kretzmann (1991, 223) writes, 'necessarily (though with the freedom associated with counterfactual choice) wills the being of something other than himself. In other words, as perfect goodness is an essential property of God and selfdiffusiveness is essential to goodness itself, the existence of other entities outside of God will be an inevitable 
consequence of God's nature. Restating this within our metaphysical context, God-who is perfectly good-must diffuse his goodness by 'grounding' the existence of all things outside of himself. The existence of other, non-fundamental (i.e. dependent or grounded) entities will be the necessary result of God's intention to produce good things. Thus, God's action of 'grounding' the existence of nonfundamental entities is a product of his nature that stems from him necessarily, yet wilfully, spreading his goodness in this creative act. ${ }^{44}$ Therefore, as God's (perfectly good) intentions are always realised, if there is a God, we can expect—with a level of certainty — that there will also be non-fundamental entities that exist alongside him. ${ }^{45}$ Theism thus fulfils Criterion (i) to a very high level.

Corresponding to this, we can also see the central claim provided by Theism - that there is a God, a metaphysically simple, omnipotence-trope-fits very well with our background knowledge as it posits the existence of certain a type of entity - a trope-that is at the foundation of contemporary metaphysics. Specifically, tropes are a

${ }^{44}$ That is, this diffusive act is not an 'impersonal emanation' of God but a personal act that include, firstly, his powers-that enable him to ground the existence of all other non-fundamental entities, secondly, his beliefs-that grounding the existence of other fundamental entities will diffuse his goodness—and, thirdly, his purposes - to diffuse his goodness by grounding the existence of all other, non-fundamental entities.

45 An objection that can be raised here is how God's perfect freedom can be preserved given the Diffusiveness Principle. Well, in answer to this, following Kretzmann (1991, 223), we can say that God's freedom of choice is solely confined to his selection of what possibilities to actualise-God is necessitated as regards to whether to ground anything, yet he is perfectly free in regards to what he is to ground. 
standard feature of most current day ontologies-where influential metaphysicians such as D.C. Williams (1953, 1986), Keith Campbell (1990), Jonathan Schaffer (2001), Peter Simons (1994), Anna-Sofia Maurin (2002, 2018), Douglas Ehring (2011), Kris McDaniel (2001) and Michael Loux (2015), all have utilised the concept of a trope within their ontological system. Moreover, tropes do not only feature in the ontological systems of various metaphysicians, but are also plausible options for dealing with various issues within contemporary philosophy. That is, tropes, amongst other things, find their use in the metaphysics of properties by providing a means for one to affirm a form of realism (Markku Keinänen et al., 2016), or, in the metaphysics of persistence and identity by providing a basis for the notions of endurance and perdurance (Benovsky, 2013), or, in the philosophy of physics by providing a philosophical basis for quantum theory and the Standard Model of elementary particles (Morganti, 2009). Plausibly, the belief in the existence of tropes is widespread in contemporary metaphysics, and thus the postulation of the existence of God, identified as a (module) trope, meshes well with other theories from the neighbouring fields within contemporary metaphysics. ${ }^{46}$ Theism thus fulfils Criterion (ii) to a significant level.

46 One could raise the objection here that the notion of a 'personal' trope is not widespread in contemporary metaphysics, and thus Theism does not mesh well with our background knowledge. In response to this issue, one can emphasise the importance of the type/token distinction for the Criterion of Background Knowledge. That is, for the postulation of the existence of an entity to be such as to fit within our background knowledge, this entity simply needs to be of a class (i.e. a type) of entities that are taken to exist within other fields; rather than it being a particular instance of this class (i.e. a token) that is regularly seen to be

Manuscrito - Rev. Int. Fil. Campinas, v. 44, n. 4, pp. 93-168, Oct.-Dec. 2021. 
Furthermore, Theism is also a very simple explanation, or, in fact, the simplest possible personal fundamental explanation, as it explains the various phenomena of reality in terms of the powerful action of one personal entity: God - rather than many personal entities — and thus it is an explanation that is quantitatively simple - it is simpler than any other polytheistic based personal explanation. However, Theism is not only quantitively simple, but it is also qualitatively simple, in the sense that it postulates the existence of the simplest kind of personal entity. As God is metaphysically simple, and thus lacks proper parts, God has the fewest number and kind of properties possible: zero. As, instead of possessing properties, each attribution made of God is numerically identical to him-God's attributes are God himself. There is thus no further explanation that is needed to be provided for why God has the properties that he does - as he does not have any properties. Furthermore, as Theism identifies God as a trope (of a modular kind), it

duplicated (as if this were in fact the case, then one would not be able to make discoveries of new instances of a given class, which one clearly can). Thus, even though God is a personal module trope- that is, he is able to be 'picked out' from the class of tropes by being personal (amongst other things) —as tropes are a class of entities that are widely taken to exist in other fields within contemporary metaphysics (outside of the field of analytic theology), the postulation of the existence of God is a postulation of a type of entity that does in fact fit within our background knowledge- even if he is a unique instance of this kind. Whereas, for example, if one were to assume Swinburne's (2016, 103-126) construal of God as an omnipresent spirit, God would indeed be a type of entity that does not fit within our background knowledge, as spirits are not widely taken to exist in other fields within contemporary metaphysics (outside of the field of analytic theology). 
posits the existence of an entity of the fewest number of kinds: one. Assuming the correctness of 'Classical Trope Theory', tropes allow one to affirm the existence of one ontological kind or category: the kind or category 'trope', with the other kinds or categories of 'substance' and 'universals' being denied. ${ }^{47}$ Thus, by Theism positing the existence of God, one only has to be committed to the existence of one ontological kind or category, and thus this type of fundamental explanation allows one to continue to have a very parsimonious ontology. Theism is thus quantitatively and qualitatively the simplest possible explanation, due to the fact that it postulates the fewest number and kind of entities: one, with the fewest number and kind of properties: zero. Theism thus fulfils Criterion (iv) as well.

Therefore, within our context of analysis, Theism provides the simplest kind of personal fundamental explanation that fits with our background knowledge and leads us to expect (with a level of certainty) the existence of all other non-fundamental entities. Theism thus fulfils all of the relevant components of our inductive criteria. The question that now presents itself is: do the other possible alternative fundamental explanations of Priority Monism and Priority Pluralism do so as well?

For Priority Monism, there is a postulation made concerning the existence of a fundamental entity: the Cosmos. This entity is identified as the spacetime manifold, with all other existing material objects being identified as

${ }^{47}$ This is due to the fact of a trope being able to play the role of a substance-through forming a compresent bundle with other tropes-and universal-through the process of abstraction enabling one to fictionally treat a class of trope as universal-like entities. 
spacetime regions that are dependent, proper parts of the Cosmos. Whereas, for Priority Pluralism, there is a postulation made concerning the existence of a collection of mereological atoms, identified as (point-particle like) module tropes, that make up, as proper parts, the larger existing concrete objects, and thus ultimately the Cosmos. For Priority Monism, there is thus the postulation of the existence of one non-fundamental entity, and for Priority Pluralism, there is the postulation of many fundamental entities. In regards to the predictive power of both explanations, it is clear that this would be significantly high, due to the fact that the existence of non-fundamental entities is entailed by the existence of the Cosmos and the collection of mereological atoms. As, on the one hand, it is inbuilt into Priority Monism that the Cosmos is the sole fundamental entity, with all other existing concrete objects being nonfundamental entities that are proper parts of the Cosmos. Thus, we can expect with a level of certainty that if the single, fundamental Cosmos exists, then the various nonfundamental entities - its spacetime regions and proper parts - will exist as well. Likewise, on the other hand, given the plausibility of the principle of unrestricted composition-the thesis that every plurality of objects compose something-it is also inbuilt into Priority Pluralism that the collection of mereological atoms are the only fundamental entities, and thus all other existing concrete objects are non-fundamental entities that are composed of these various atoms- the nonfundamental entities are decomposable into these very atoms. ${ }^{48}$ Thus, we can also expect with a level of certainty

48 The holding of the principle of unrestricted composition is important if a priority pluralist is to transition in their argument from the existence of the mereological atoms to these atoms composing other objects. However, despite its plausibility, the principle of unrestricted composition is indeed controversial, and 
that if the many fundamental mereological atoms exist, then the various non-fundamental entities will exist as well. Both of these explanations thus fulfil Criterion (i) very well. Furthermore, it is quite clear that Priority Monism and Priority Pluralism fit well with our background knowledge, given that the postulation of the Cosmos, for the former, and mereological atoms, for the latter, does not seem to conflict with anything else within the fields of contemporary metaphysics. Rather, though it is a debated thesis, ${ }^{49}$ the notion of substantivalism - the position that the Cosmos is a spacetime substance that is non-derivative (i.e. fundamental) — which is a thesis that is at the heart of the particular conception of Priority Monism assumed here-is taken by various philosophers to be a potentially correct understanding of the nature of the Cosmos. ${ }^{50}$ Furthermore, as noted previously, the concept of a trope is also a widely

so a proponent of Priority Pluralism will need to support this principle if this position is to be taken alongside Theism and Priority Monism as a candidate fundamental explanation that has some level of predictive power. Nevertheless, in order to retain Priority Pluralism as a potential candidate for our explanatory target, the veracity of this principle will be assumed rather than argued for here-which is not problematic given that this article focuses on defending Theism rather than that of Priority Pluralism.

${ }^{49}$ As is (nearly) every notion in contemporary philosophy.

50 More specifically, the particular conception of substantivalism that is at the centre of the version of Priority Monism here is that of super-substantivalism - the view that the Cosmos is a spacetime substance that is the only fundamental entity. Nevertheless, the notion of substantivalism is at the core of this specific position, which is simply an additional numerical thesis. For a further explanation of substantivalism and the various conceptions of it on offer, see (Huggett and Hoefer, 2015).

Manuscrito - Rev. Int. Fil. Campinas, v. 44, n. 4, pp. 93-168, Oct.-Dec. 2021. 
used notion within the various fields of contemporary metaphysics. Therefore, Criterion (ii) is clearly fulfilled to a sufficient level by these two explanations as well. Thus, the question now is: do these two explanations meet the final Criterion - the Criterion of Simplicity — as well? The answer to this is quite clearly no. As Priority Monism is quantitatively simple, but fails to be qualitatively simple, and Priority Pluralism is qualitatively simple, but fails to be quantitatively simple. That is, on the one hand, Priority Monism postulates the existence of one fundamental concrete object: the Cosmos, and thus postulates the existence of the fewest number of entities - one. Yet, it does not postulate the fewest kinds of entities or the fewest number or kinds of properties. That is, for the former, it fails to do this by assuming a twocategory ontology-substance and attribute/tropes-where the Cosmos is the one fundamental substance that instantiates various universals, or is constituted by various tropes. Therefore, if one is thus to affirm the veracity of Priority Monism, then one must also affirm the veracity of this type of ontology, and therefore be saddled with the issues that are present within this type of ontology (such as Bradley's Regress)..$^{51}$ Moreover, for the latter, as the Cosmos is the spacetime manifold that has material objects as proper parts of it in the form of spacetime regions, the properties of these material objects are 'pinned' onto the Cosmos itself. The Cosmos thus instantiates a nearly infinite number of properties. The Cosmos, as construed in this way, would thus be many propertied, which renders Priority Monism as

51 This conclusion, however, is only reached by the version of Priority Monism that has been assumed throughout this article. I thus leave it as an open issue for further research whether other conceptions of Priority Monism (such as Priority Monism combined with nominalism) must also reach this conclusion. 
qualitatively complex rather than simple. On the other hand, we have Priority Pluralism which postulates the existence of many fundamental objects - many mereological atoms, that, as module tropes would be metaphysically simple — and thus, it posits the existence of the fewest number and kind of properties-zero properties. Yet, as there needs to be a nearinfinite number of existing mereological atoms for the composition of the variety of actual material objects. There are thus many mereological atoms, which renders Priority Pluralism as quantitatively complex rather than simple. These two explanations both fail to fulfil Criterion (iv) and thus together posit explanations that predict the data at hand and fit with our background knowledge, but, nevertheless, are complex.

\subsection{Comparison of the Candidates}

In regards to the occurrence of our explanatory targetthe existence of non-fundamental entities - we have three candidate fundamental explanations: Theism, Priority Monism and Priority Pluralism. All of these explanations fit with our background knowledge and yield (or predict) the data to an extremely high level. However, what we find with two of these explanations: Priority Monism and Priority Pluralism, is that there is a postulation made concerning the nature of certain fundamental entities - the Cosmos or collection of mereological atoms - that is complex and thus less simple than the postulation made by Theism. Theism, as noted above, postulates the existence of one fundamental entity: God. This single fundamental entity is a metaphysically simple omnipotence trope (who is identical to each of the attributes ascribed to him) and thus instantiates zero properties. Theism, unlike Priority Pluralism, postulates the fewest number of entities — one module trope, 
rather than many-and, unlike Priority Monism, it postulates the fewest kind of entities - one kind: trope, rather than (at least) two kinds: substance and attributes — and the fewest number and kind of properties_zero properties, rather than many. Thus, in comparison to Priority Monism and Priority Pluralism, Theism is a simpler explanation of explanatory target. In other words, Theism fulfils our inductive criteria to a greater extent than the alternative inanimate fundamental explanations. And thus, given this, we have a good reason to take these latter explanations as solely being full metaphysical explanations (i.e. metaphysical explanations that fully explain the data, yet have a further synchronic explanation for them), rather than fundamental explanations (i.e. metaphysical explanations that fully explain the data and do not have a further synchronic explanation for them), that can each serve as a terminus in explanation for the existence of non-fundamental entities. More specifically, as noted previously, if one can formulate an explanation that allows us to have a metaphysical explanation with a greater fulfilment of our inductive criteria-in this case, a simpler explanation-than the existing options, without also there being a corresponding loss in the fulfilment of any other of the components of the criteria, such as fit with background knowledge or predictive power, then we have good reason to adopt that explanation as being the fundamental explanation for our explanatory target. Theism, in comparison to Priority Monism and Priority Pluralism, is the simplest explanation, fitting with our background knowledge, that leads us to expect the existence of the nonfundamental entities that are part of the layered structure of reality.

Importantly, however, taking Theism to be the fundamental explanation of our explanatory target does not mean that we need to do away with Priority Monism or Priority Pluralism as, in fact, the central theses of these 
notions can still be affirmed - which, for Priority Monism, is that of the whole being prior to its parts, and thus metaphysical explanation dangling downwards, and, for Priority Pluralism, is that of the parts being prior to the whole, and thus metaphysical explanation snaking upwards. Theism thus postulates the existence of a single fundamental entity: God, who, if Priority Monism is true, grounds the Cosmos - and thus explanation dangles downward from him through the Cosmos to everything else. Or, if Priority Pluralism is true, God is the sole fundamental who grounds the collection of mereological atoms - and thus explanation snakes upwards from him through the mereological atoms to everything else. Therefore, given this, within the scientific or categorial layered view of reality that was detailed previously, we do, in fact, have good reason to descend further down the chain and levels, beyond that of physics category, ${ }^{52}$ to a stopping point within the theology category. This descent, and the role that God plays within a priority monist or priority pluralist framework, will look as such:

52 Which will include either Priority Monism or Priority Pluralism within that category.

Manuscrito - Rev. Int. Fil. Campinas, v. 44, n. 4, pp. 93-168, Oct.-Dec. 2021. 

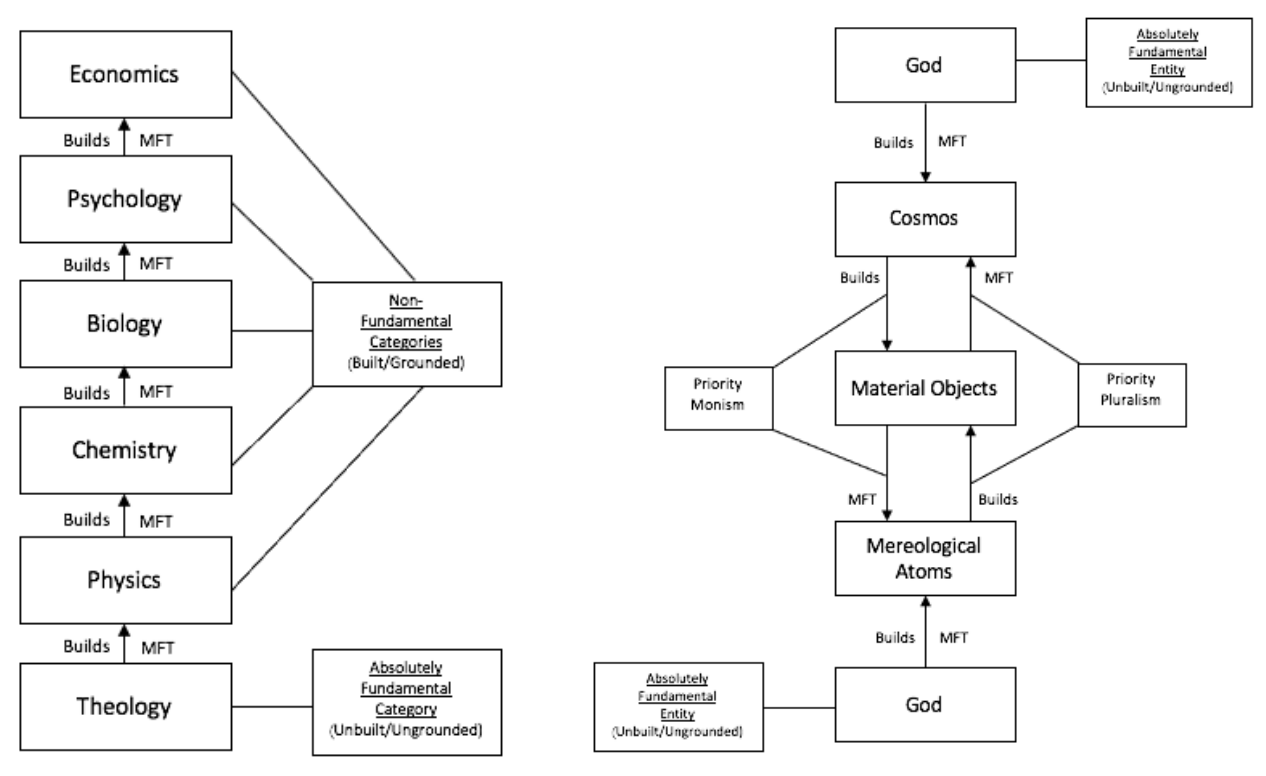

\section{Fig 1.5 Layered and Theistic Priority Monism and Pluralism Structure}

By making this descent to the theology category, we reach our terminus in explanation for the existence of nonfundamental entities. That is, God, the entity studied by theology, is thus the sole fundamental entity within the layered structure of reality by him not being the output of any building relation, in that nothing 'presses upwards' on him, rather he presses upwards on all other (non-fundamental) entities. More precisely, God fulfils the following roles as the sole entity that exists in the fundamental layer of reality: 


\begin{tabular}{|l|l|l|}
\hline $\begin{array}{l}\text { Fundamentality } \\
\text { Prounding) }\end{array}$ & Independent (Ungrounded) & Complete (Ground) \\
\hline Directed & $\begin{array}{l}\text { God does not rank below any } \\
\text { other entity in the hierarchical } \\
\text { structure of reality. }\end{array}$ & $\begin{array}{l}\text { God ranks higher than any } \\
\text { other entity in the } \\
\text { hierarchical structure of } \\
\text { reality within the specific } \\
\text { world in which he exists. }\end{array}$ \\
\hline Necessitating & $\begin{array}{l}\text { The existence of any other } \\
\text { entity does not necessitate the } \\
\text { existence of God. }\end{array}$ & $\begin{array}{l}\text { God's existence necessitates } \\
\text { the existence of every other } \\
\text { entity within the specific } \\
\text { world in which he exists. }\end{array}$ \\
\hline Generative & $\begin{array}{l}\text { God's existence and intrinsic } \\
\text { nature are not fixed by the } \\
\text { existence and intrinsic nature of } \\
\text { any other entity. }\end{array}$ & $\begin{array}{l}\text { God's existence and } \\
\text { intrinsic nature fixes the } \\
\text { existence and intrinsic } \\
\text { nature of every other entity } \\
\text { within the specific world in } \\
\text { which he exists. }\end{array}$ \\
\hline Explanatory & $\begin{array}{l}\text { God's existence, at a specific } \\
\text { time, is not explained by the } \\
\text { existence of any other entity. }\end{array}$ & $\begin{array}{l}\text { God's existence, at a specific } \\
\text { time, explains the existence } \\
\text { of all other entities within } \\
\text { the specific world in which } \\
\text { he exists. }\end{array}$ \\
\hline Causal & $\begin{array}{l}\text { God is not a grounded effect of } \\
\text { any other entity and thus is not } \\
\text { Equation Model. }\end{array}$ & $\begin{array}{l}\text { God is the metaphysical } \\
\text { cause of all other entities } \\
\text { that are grounded effects, } \\
\text { and thus is the input of a } \\
\text { Structural Equation Model } \\
\text { within the specific world in } \\
\text { which he exists. }\end{array}$ \\
\hline
\end{tabular}

Table 1. 2 Fundamentality Principles (ii) 
God thus acts as the fundamental source of all of realityhis existence is sufficient for the existence of all other, nonfundamental entities at any given time, ultimately backing a synchronic metaphysical explanation for them existing as they do. The existence of God thus provides a sufficient fundamental explanation for there being non-fundamental entities, rather than none. And, importantly, we do not need to search for a further explanation beyond God, as being a metaphysically simple entity that exists fundamentally (i.e. is independent and complete), his existence is inexplicable, and his building agency, with the operation of the laws of metaphysics (i.e. grounding principles), necessitates the existence of all other non-fundamental entities. The layered structure of reality terminates in God, and God alone. And thus, given this, we have a successful abductive argument for the existence of God, by the postulation of his existence providing us with the best, or more specifically, the only true fundamental explanation for the existence of the nonfundamental entities that fill up the various levels of the layered structure of reality. We thus have one more good reason to believe in the existence of God.

\section{Conclusion}

In conclusion, in section one an explanatory framework was established, which provided us with the needed tools: an inductive criteria, to assess the potential worth of a given metaphysical explanation. In section two, our explanatory target was detailed: that of the existence of non-fundamental entities, rather than none. And the nature of this explanatory target was further elucidated within a cetin metaphysical picture concerning the layered structure of reality. In section three, candidates for a fundamental explanation of our explanatory target were detailed and assessed for their 
fulfilment of our inductive criteria, these candidates were: Theism, Priority Monism and Priority Pluralism. In this assessment, Theism was shown to be an explanation that fulfils the inductive criteria to a greater level than the alternative explanations of Priority Monism and Priority Pluralism. Thus, Theism provides the simplest explanation, fitting with our background knowledge, that leads us to expect the existence of non-fundamental entities, when otherwise they would not be expected to exist. Theism is the sole true fundamental explanation of our explanatory target. And, therefore, given the existence of non-fundamental entities, we thus have one more good (abductive) reason to believe that God, the single, absolutely fundamental entity exists as well.

\section{References}

Alvarado, J. 2019. Are Tropes Simple?. Teorema 38: 51-72. Audi, P. 2012. Grounding: Toward a Theory of the InVirtue-Of Relation. Journal of Philosopby 109: 685-711.

Bennett, K. 2011. By Our Bootstraps. Philosophical Perspectives 25: $27-41$.

Bennett, K. 2017. Making Things Up. Oxford: Oxford University Press.

Benovsky, J. 2013. New Reasons to Motivate Trope Theory: Endurantism and Perdurantism. Acta Anal 28: 223227. https://doi.org/10.1007/s12136-012-0166-0

Bliss, R. 2019. What Work the Fundamental?. Erkenntnis 84: 359-379. https://doi.org/10.1007/s10670-017-99627

Cameron, R. 2008. Turtles all the Way Down: Regress, Priority, and Fundamentality. The Philosophical Quarterly 58, 1-14. https://doi.org/10.1111/j.14679213.2007.509.x 
Campbell, K. 1990. Abstract Particulars. Oxford: Blackwell. Dixon, T. S. 2016. What Is the Well-Foundedness of Grounding?. Mind 125: 439-468. https://doi.org/10.1093/mind/fzv112

Douven, I. Abduction. Stanford Encyclopedia of Philosophy.

https://plato.stanford.edu/archives/sum2021/entrie s/abduction/

Ehring, D. 2011. Tropes: Properties, Objects and Mental Causation Oxford: Oxford University Press.

Fine, K. 2012. Guide to Ground, In Metaphysical Grounding: Understanding the Structure of Reality, eds. Fabrice Correia and Benjamin Schnieder, 37-80. Cambridge: Cambridge University Press.

Fisher, A.R.J. 2018. Instantiation in Trope Theory. American Philosophical Quarterly 55.2: 153-164.

Fisher, A.R.J. 2020. Abstracta and Abstraction in Trope Theory. Philosophical Papers 49.1: 41-67. https://doi.org/10.1080/05568641.2019.1571938

Garcia, R. 2015a. Two Ways to Particularize a Property. Journal of the American Philosophical Association 1: 635652. https://doi.org/10.1017/apa.2015.21

Garcia, R. 2015b. Is Trope Theory a Divided House?. In The Problem of Universals in Contemporary Philosophy, ed. Gabrielle Galluzzo and Michael Loux, 133-155. Cambridge: Cambridge University Press.

Garcia, R. 2015c. Tropes as Divine Acts: The Nature of Creaturely Properties in a World Sustained by God. European Journal for Philosophy of Religion 7.3: 105-30. https://doi.org/10.24204/ejpr.v7i3.107.

Garcia, R. 2016. Tropes as Character-Grounders. Australasian Journal of Philosophy 94: 499-515. https://doi.org/10.1080/00048402.2015.1106567 
Huggett, N. and Hoefer, C. Absolute and Relational Theories of Space and Motion. Stanford Encyclopedia of Philosophy. https://plato.stanford.edu/archives/spr2018/entries /spacetime-theories/

Keinänen, M., Hakkarainen J., Keskinen A. 2016. Why Realists Need Tropes. Metaphysica 17:69-85. https://doi.org/10.1515/mp-2016-0006

Korbmacher, J. 2018. Axiomatic Theories of Partial Ground I. Journal of Philosophical Logic 47: 161-191. doi:10.1007/s10992-016-9423-9

Kretzmann, N. 1991. A general problem of creation: why would God create anything at all?, In Being and Goodness: The Concept of the Good in Metaphysics and Philosophical Theology, ed. Scott MacDonald, 208-228. New York: Cornell University Press.

Leuenberger, S. 2013. Grounding and Necessity. Inquiry 57: 151-174. https://doi.org/10.1080/0020174X.2013.855654

Loux, M. 2015. An exercise in constituent ontology. In The Problem of Universals in Contemporary Philosophy, eds. Gabrielle Galluzzo and Michael Loux, 9-45. Cambridge: Cambridge University Press.

Maurin, A-S. 2002. If Tropes. Dordrecht: Kluwer Academic Publishers.

Maurin, A-S. 2018. Tropes. Stanford Encyclopedia of Philosophy.

https://plato.stanford.edu/entries/tropes/.

Maurin, A-S. 2019. Grounding and metaphysical explanation: it's complicated. Philosophical Studies 176, 1573-1594. https://doi.org/10.1007/s11098-0181080-0 
McDaniel, K., 2001. Tropes and Ordinary Physical Objects. Philosophical Studies 104: 269-290. https://doi.org/10.1023/A:1010310503120

Molnar, G. 2003. Powers: A Study in Metaphysics. Oxford University Press: Oxford.

Morganti, M. 2009. Tropes and Physics. Grazer Philosophische Studien 78: 185-205. https://doi.org/10.1163/9789042026056_009

Morganti, M. 2014. Metaphysical Infinitism and the Regress of Being. Metaphilosophy 45: 232-244. https://doi.org/10.1111/meta.12080

Phillipse, H. 2012. God in the Age of Science? A Critique of Religious Reason. Oxford: Oxford University Press.

Rabin, G., Rabern, B. 2016, Well Founding Grounding Grounding, Journal of Philosophical Logic 45: 349-379. https://doi.org/10.1007/s10992-015-9376-4

Raven, M. 2015. Ground. Philosophy Compass 10: 322-333. https://doi.org/10.1111/phc3.12220

Raven, M. 2020. (Re)discovering Ground, In The Cambridge History of Philosophy, 1945-2015, eds. Kelly Becker and Iain D. Thomson, 147-159. Cambridge: Cambridge University Press.

Rodriguez-Pereyra, G. 2015. Grounding is not a Strict Order. Journal of the American Philosophical Association 1: 517-534. https://doi.org/10.1017/apa.2014.22

Rosen, G. 2010. Metaphysical Dependence: Grounding and Reduction, In Modality: Metaphysics, Logic, and Epistemology, eds. Bob Hale and Aviv Hoffmann, 10936. Oxford: Oxford University Press.

Schaffer, J. 2001. The Individuation of Tropes. Australasian Journal of Philosophy 79: 247-259. https://doi.org/10.1080/713659225

Schaffer, J. 2009a. On What Grounds What, In Metametaphysics: New Essays on the Foundations of 
Ontology, eds. David Manley, David J. Chalmers \& Ryan Wasserman, 347-383. Oxford: Oxford University Press.

Schaffer, J. 2009b. Spacetime the one substance. Philosophical Studies 145: 131-148. https://doi.org/10.1007/s11098-009-9386-6

Schaffer, J. 2010. Monism: The Priority of the Whole. Philosophical Review 119: 31-76.

Schaffer, J. 2012. Grounding, transitivity and contrasitivity, In Metaphysical Grounding: Understanding the Structure of Reality, eds. Fabrice Correia and Benjamin Schnieder, 122-138. Cambridge: Cambridge University Press.

Schaffer, J. 2013. The Action of the Whole. Proceedings of the Aristotelian Society Supp 87: 67-87. https://doi.org/10.1111/j.1467-8349.2013.00220.x

Schaffer, J. 2015. What Not to Multiply Without Necessity. Australasian Journal of Philosophy 93: 644-664. https://doi.org/10.1080/00048402.2014.992447

Schaffer, J. 2016. Grounding in the image of causation. Philosophical Studies 173: 49-100. https://doi.org/10.1007/s11098-014-0438-1

Schaffer, J. 2018. Laws for Metaphysical Explanation. Royal Institute of Philosophy Supplement 82: 1-22. https://doi.org/10.1017/S1358246118000164

Schaffer, J. 2021. Ground Functionalism, In Oxford Studies in Philosophy of Mind 1, ed. Uriah Kriegel, 171-207. Oxford: Oxford University Press.

Sijuwade, J. 2021a. Divine Simplicity: The Aspectival Account. European Journal for Philosophy of Religion: 1-37. https://doi.org/10.24204/ejpr.2021.3306

Sijuwade, J. 2021b. Building the monarchy of the Father.

Religious

Studies: $1-20$. doi:10.1017/S0034412521000020 
Simons, P. 1994. Particulars in Particular Clothing: Three Trope Theories of Substance, Philosophy and Phenomenological Research, 54: 553-575.

Simons, P. 2020. Atoms and tropes, In Atomism in Philosophy A History from Antiquity to the Present, ed. Ugo Zilioli, 430-441. London: Bloomsbury Academic.

Swinburne, R. 2001. Epistemic Justification. Oxford: Oxford University Press.

Swinburne, R. 2004. The Existence of God. Oxford: Oxford University Press.

Swinburne, R. 2010. Is There a God?. Oxford: Oxford University Press.

Swinburne, R., 2016. The Coherence of Theism: Second Edition. Oxford: Oxford University Press.

Trogdon, K. 2013. An Introduction to grounding, In Varieties of Dependence: Ontological Dependence, Grounding, Supervenience, Response-Dependence, ed. Benjamin Schnieder, Miguel Hoeltje and Alex Steinberg, 97-122. Berlin: Philosophia Verlag.

Williams, D.C. 1953. On the Elements of Being II. Review of Metaphysics 7: 171-192.

Williams, D.C. 1986. Universals and Existents. Australasian Journal of Philosophy 64: 1-14. https://doi.org/10.1080/00048408612342191

Wilson, A. 2018. Metaphysical Causation. Noûs, 52: 723-751. https://doi.org/10.1111/nous.12190

EY 